\title{
Underground MRT in Kuala Lumpur - The Inevitable Urban Transit Solution
}

\author{
(Date received: 29.6.2018/Date accepted: 06.09.2018) \\ Dato' Ir. Paul Ha Tiing Tai \\ BEng (Hons.), FIEM, FICE, FIStructE, PEng \\ Deputy Group Managing Director \\ Gamuda Berhad
}

\begin{abstract}
The traffic congestion in Kuala Lumpur and the high demand for urban space would inevitably lead to an underground transit system. The underground works will be posed with all the constraints and challenges in both design and construction that is unique to Kuala Lumpur's geology, land use and social-economic structure. The successfully completed underground section of the Sg. Buloh to Kajang (SBK), Klang Valley Mass Rapid Transit (KVMRT) Project between Semantan and Maluri was based on a design and build contract by MMC Gamuda Joint Venture. This paper presents the engineering challenges related to deep excavation and tunnelling in the different geology encountered along the SBK line which include but not limited to the topics highlighted hereafter. The design of deep excavation, temporary retaining systems and other associated works for stations and its performance in Kenny Hill and Kuala Lumpur Limestone. The tunnelling works connecting all the underground stations including the innovative variable density tunnel boring machine, the risk management process, building damage assessment/protection and monitoring particularly to verify the performance of unconventional construction sequence. This paper also make reference to the efforts made to develop the human resource in order to meet the tight construction program. The successful completion of the project is only possible with the dedication and commitment of the client, the management and the support of the many dedicated staff who had laboured tirelessly to complete the project on time and in a safe manner. The valiant effort and cooperation of various parties are gratefully acknowledged without which the subject matter of this lecture would not have been possible.
\end{abstract}

Keywords: Deep Excavation, Karsts, Kenny Hill Formation, Kuala Lumpur Limestone, Risk Management, TBM, Tunnelling, Tunnel Boring Machine.

\subsection{INTRODUCTION}

The traffic congestion in Kuala Lumpur, the time loss in travelling, the increased carbon footprint, the uncertainty in travel times is an impediment to productivity and a "turn off" to investors. To address these concerns, the government has identified that an integrated sustainable transportation system is of paramount importance to the Economic Transformation of Greater Kuala Lumpur/Klang Valley National Key Economic Area (Greater KL/KV KREA). The mass rapid transit project, namely the MRT project from Sg. Buloh to Kajang (SBK) line is pivotal in realising the objective of achieving the target of $50 \%$ of all trips to be done by using public transport by the year 2020. The high demand for urban space has led to the use of underground space for car parks, commercial activities, public transportation systems and pedestrian/vehicular access. The SBK alignment in downtown KL had gone underground due to the lack of a suitable at grade or elevated corridor. Going underground had the advantage of maintaining the current skyline or "cityscape" and the least social and environmental impact as the construction activities were conducted underground. The disposal of tunnel muck and the supply of tunnel segments and other construction materials were managed from within the tunnel between the work fronts and surface support facilities sited at a convenient location with least inconvenience or impact to the public. The $9.3 \mathrm{~km}$ underground section which included seven underground stations and twin bored tunnels was awarded to MMC Gamuda Join Venture (MGKT) as a design and build contract. In general, deep excavation and tunnelling in urban or built environment is very challenging and entails high risks. These challenges and risks had been mitigated/managed through design, construction planning and execution, selecting the right tools and machinery for the job and some of these measures undertaken from design to completion of the project is presented in this paper.

\subsection{GENERAL GEOLOGY}

From Figure 1, the general geology map of Map of Kuala Lumpur, the SBK alignment traverses through about $5.3 \mathrm{~km}$ of Kenny Hill Formation and the remaining $4.0 \mathrm{~km}$ is in $\mathrm{KL}$ Limestone Formation. The SBK line has 7 underground stations and four of the underground stations namely KL Sentral, Pasar Seni, Merdeka and Bukit Bintang Station are within the Kenny Hill Formation whilst three underground stations namely, Pasar Rakyat, Cochrane and Maluri Station are within the KL Limestone Formation.

The Kenny Hill Formation is predominantly a sequence of interbedded sandstone, siltstones and shales/mudstones overlain by stiff over-consolidated soils predominately of sandy silty Clay and Silty Sand. The Kenny Hill Formation had undergone metamorphism resulting in quartzite and schist/ phyllite. The variability in thickness of the hard soil and depth of metamorphosed sedimentary rock for each station present unique design and construction challenges as well as the selection of an optimal type of deep retention wall system. 


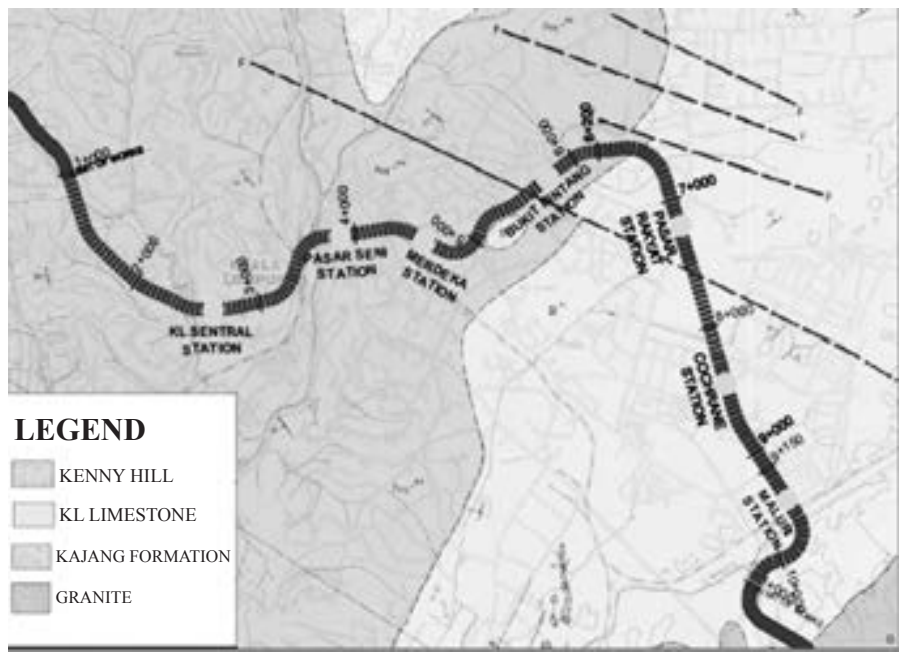

Figure 1: KVMRT alignment with underground stations superimposed on the Geology Map of Kuala Lumpur (1993)

The Kuala Lumpur Limestone Formation along the alignment is composed of fine to coarse grained, white to grey, predominantly recrystallised limestone, with local developments of dolomitic limestone. The alluvium is underlain by a highly irregular bedrock containing an intricate three-dimensional network of voids and solution channels. These features are consistent with Extreme Karst classification according to Waltham \& Fookes (2003). This Karstic feature poses many problems to tunnelling as well as the design and construction of deep underground retention structures. The irregular rock levels and the unknown rock quality necessitate the selection of flexible and robust retention systems to cope with such variabilities. At locations with shallow bedrock, grout cut off systems are required to prevent high water inflows and development of sinkholes during excavation. Some of the karsts features reported or encountered in KL limestone have been presented by Tan (2005) and Yeap (1986).

\subsection{MRT UNDERGROUND WORKS}

In order to meet the transit objectives and safety requirements of the underground section of the MRT line, the following underground structures form an integral part of the underground transit system, namely, underground stations, cross overs and cross passages as well as ventilation and escape shafts. The cross passages and adits will not be covered in this paper, the major components of deep excavation of underground stations and tunnelling will be presented.

In order to ensure the success of the underground works, we have to ensure that the following must be in place;

- we have right type of plant and machinery

- right tunnel boring machine deployed at the right ground or geological formation

- have the right mix in human resource and experienced or trained skill workers

- experienced designers and planners

- experienced operators

- good safety and health procedures

- good temporary works designers and managers

- effective management of suppliers and subcontractor

- risk management plan and tracking

- seamless interfacing, etc.
The major underground works for the SBK line were the stations and tunnelling works. It was imperative that in this design and build contract with a very tight schedule, the design and construction teams must be fully engaged to provide updated information to the planner. This has minimised potential delays and program clashes. Delinking the tunnelling and station box construction and optimized the number of TBMs to match the space or sites available to launch and support the tunnelling activities had been considered to minimise program risks and project delays.

For station box construction, the selection of the type of retention system should take into consideration of the ground condition as well as the market supply chain of specialist contractors especially when all the works are expected to commence concurrently. In this class of works, the highest risk is probably ground related risks.

In deep excavation work, the selection of the right retention system, efficient temporary support system with adequate redundancy coupled with an efficient or construction friendly design will be the key to success. The method of construction and works stages may have a significant impact to the works and the surrounding environment and structures. In some cases, ground treatment works may be required to improve the subsurface properties to provide the level improvement required for the works (for example strength, stiffness or permeability, etc.).

The selection TBM is somewhat governed by the geology, the rock type and its consequential soil derivatives. In SBK line two types of TBM were proposed, EPBs were proposed for Kenny Hill Formation and Variable density (VD) TBM was selected for Kuala Lumpur Limestone Formation.

\subsection{Managing Deep Excavation Works}

Deep excavation works especially for underground metro stations would take a few years to complete and they are normally located in a built environment. Hence, the deep excavation works will inevitably require some form of ground water and lateral/vertical deformation control during excavation. The depths of excavation, the ground conditions and the land use around the excavation, governs the method of groundwater control and groundwater level preservation. In relatively shallow excavation or green field environment, dewatering could be feasible. In reality, some form of cut-off system is necessary in minimising seepage and migration of fines into the excavation over the long construction period anticipated. As such, a trench type retention system (e.g. diaphragm walls) or some form of interlocking retention systems (sheet piles, bored piles, jet grouting and deep soil mixing) would be plausible systems to retain the overburden soil and to provide a "cut-off" to seepage flow into the excavation. This method is often used in conjunction with ground water recharging at locations where groundwater lowering has been identified to have a significant impact on the neighbouring structures or environment.

The design and build contractor selection of type of retention system are contingent upon a number of factors such as; design requirement, ground condition, site constraints, environmental impacts, program, construction consideration and cost factors. Below are listed several common temporary retention systems for deep excavation in urban environment:

i. Open cut / Stabilised Slope (Nails, geotextile, etc)

ii. Soldier piles and timber lagging 
iii. Sheet pile walls

iv. Cement - Soil Mix Walls

v. Contiguous Bored Pile Wall

vi. Secant Pile Walls

vii. Diaphragm Walls

The concept design selection process begins with brain storming all the available commonly available types of retention systems listing it down in a matrix/table to check if it can meet the desired factors and requirements and then assessing the merits of the system in the entirety. A brief discussion of the above systems is presented below.

\subsubsection{Open Cut}

The cheapest excavation method in soil would be to carry out open excavation with dewatering. However, in an urban environment involving deep excavation, this approach is generally not advisable due to safety, social, environmental and impacts on existing buildings. Furthermore, if the excavation is carried out in ex-mine tailings, the slope is expected to be relatively gentle, otherwise, it is prone to slope instability (Tan and Ch'ng, 1986).

\subsubsection{Soldier Piles Timber Lagging}

Traditional soldier pile timber lagging retaining wall is formed by first installing I beams to support the timber laggings that are slotted in as excavation progresses (see Figure 2). Soldier pile timber lagging should only be used where the impact of groundwater lowering is innocuous to the environment and neighbouring structures as the system is inherently leaky. In some cases, well-point dewatering are used together with this system to bring the water table to a level below the excavation (see Figure 2).

\subsubsection{Sheet Pile Wall}

Sheet pile wall may be used where the depths of excavation is relatively shallow and sufficient embedment can be installed to ensure stability together with the strutting system adopted. The suitability of this relative more flexible retention system is limited for the deep excavation expected for metro stations where very small deflections and settlements are permissible during excavation.

\subsubsection{Contiguous Bored Pile (CBP) Wall}

For relative less pervious soils, closely spaced CBP is quite commonly adopted as the retaining wall for basements with some provision for grouting the gaps between the bored piles. For the SMART project, an innovative "interlocking" CBP wall was adopted for the cut and cover ingress/egress tunnel below the existing Jalan Sg. Besi and next to Sg. Kerayong.

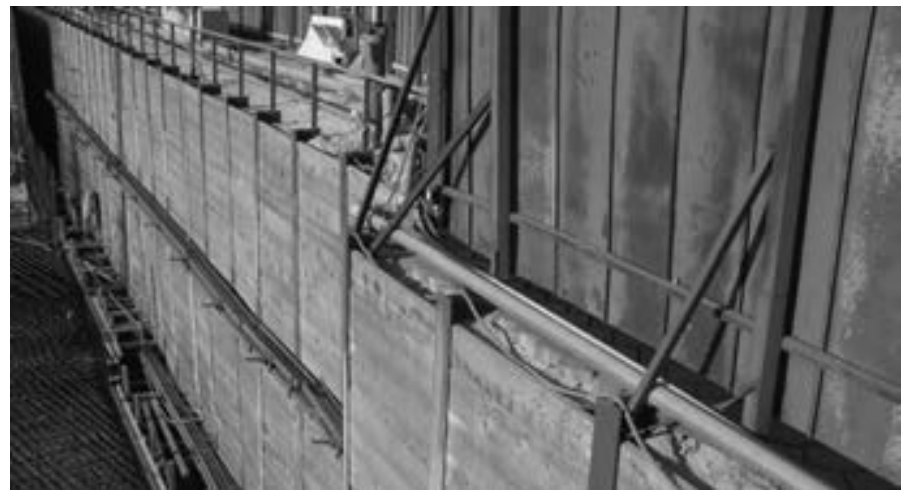

Figure 2: Soldier pile timber lagging with well point dewatering
The intermediate piles were designed to have a thicker cover to the reinforcements to permit overcutting without hitting the reinforcements. In order to meet the desired objectives, tight construction control in terms of setting out and construction tolerances were enforced. The excavation was successfully completed and the interlocking CBP was reported to work as intended.

\subsubsection{Secant Bored Pile (SBP) Wall}

An improvement to the CBP wall would be the use of interlocking SBP to ensure better exclusion of the ground water inflow into the excavated shaft (see Tan et al., 2015). It is generally accepted that SBP wall is the "best" retention system in KL limestone to tackle the highly variable rock head and the double wall casing used to install the piles are relatively innocuous to the adverse effects of solution channels and cavities during bored pile installation.

\subsubsection{Deep Soil Mixing (DSM) Wall}

DSM wall system has been used to retain the soil overburden in several excavation projects in Kuala Lumpur limestone, this system has the advantage of being a gravity retention system and the need of additional retention or strutting may be avoided. This system was reported by Goh et al., (2015) to retain the overburden soil at the SBK line south portal at Maluri, Cheras. The above constraints make this an ideal system where encroachment of ground anchors into the tunnel horizon and private properties were "not permitted".

In forming the DSM columns, the paddles for cement soil mixing are normally located at some distance above the toe of the mixing assembly. This configuration does not have any impact for the gravity structure formed fully in soil. However, the DSM column at rock soil interface may be affected by the mixing assembly and undulating rockhead (see Figure 3). As such, consideration should be made on the potential sliding and seepage path at this horizon. In order to ensure or to minimise the potential impact of this "untreated" zone of the DSM block, consolidation grouting may be considered at the interface between the base of the DSM wall and bedrock.

\subsubsection{Jet Grout Pile (JGP) wall}

At locations where the retention wall is required at locations where there is a high density of utilities JGP offers the flexibility of using small diameters holes (suitable for monitor rod access) to form large diameter column (up $3.0 \mathrm{~m}$ ) below the utilities and the flexibility to terminate the jet grout column at any depths. However, this method is not environmentally friendly due to fairly large quantity of waste grout slurry being discharged during the process. The use of JGP gravity wall for encumbrance free pile cap construction was reported by Boon et al., (2015) (see Figure 4).

\subsubsection{Diaphragm Wall (D Wall)}

D Wall is the most common retention system adopted for basement works in Kenny Hill Formation and is discussed in more detail in the sections below. However, where the excavation depths are shallow and multiple stages of forming the retaining wall are required due to site constraints, major traffic management or utility relocations; secant bored piles and where possible sheet piles are used as it is more efficient and require less plant and ancillaries. 


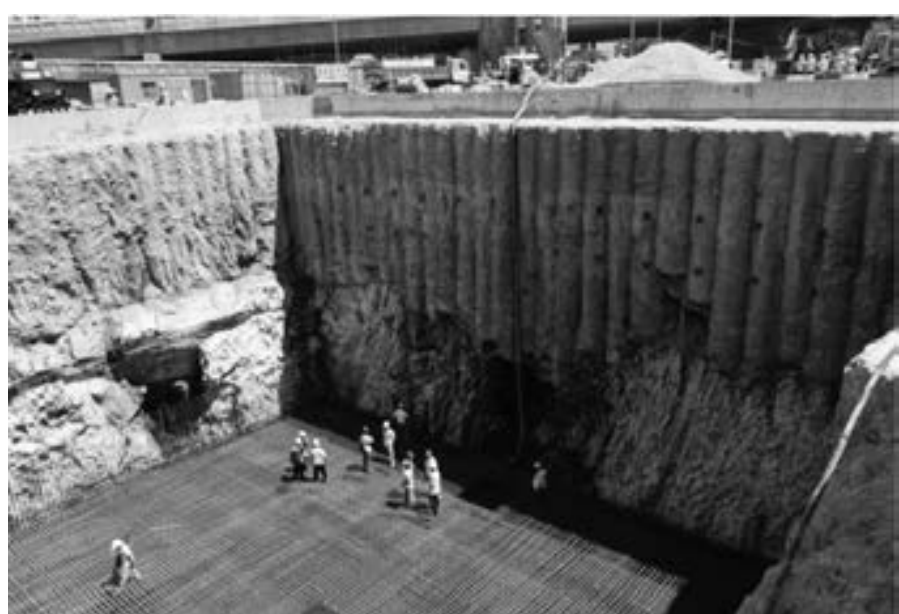

Figure 3: Deep Soil Mixing Wall on undulating rockhead

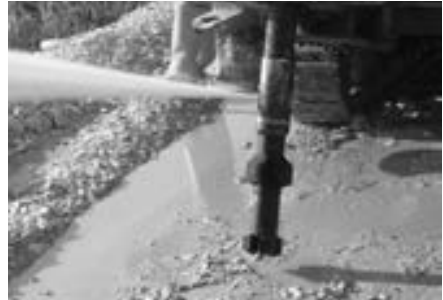

Figure 4a: Jet grout assembly showing jetting location above drill bit

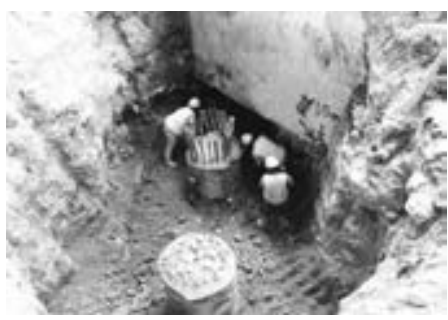

Figure 4b: Jet grouting surrounding excavation for the construction of transfer slab for pile underpinning (after Boon et al., 2015)

Table 1 is a summary of the type of temporary retention system selected for the seven underground stations of SBK line.

\subsection{MANAGING DEEP EXCAVATIONS IN KENNY HILL}

Tan et al., (2015) reported some of the challenges encountered in the design and construction of the Diaphragm wall (D-wall) in Kenny Hill formation and some of the considerations are reproduced below.

i. Thickness of D-wall - The thickness of the D-walls in this project varies from 0.8 to $1.2 \mathrm{~m}$. In addition to the depth of excavation; the thickness of the D-wall was very much influenced by the spacing of temporary and permanent lateral supports and construction sequence adopted. For this project, higher steel content of typically between 2.5 to $4.6 \%$ was used to manage the above considerations and to standardize the wall thickness. However, the use of higher steel content must be balanced with the concrete quality and finishing achievable for the D-wall.

For example, for the bottom up Merdeka station, Dwall with $1.2 \mathrm{~m}$ thickness and up to $6.7 \mathrm{~m}$ wide was selected with 6 level of struts spaced at between $3.5 \mathrm{~m}$ to $6 \mathrm{~m}$ and steel content was approximately 2.5 to $3 \%$. While the top down Bukit Bintang station, a $1.2 \mathrm{~m}$ thick D-wall was adopted with higher steel content of between 3.7 to $4.6 \%$ because of the larger slab spacing, deeper depth and poorer soil condition.

ii. Panel Width - D-wall panel width can vary from 2.8 to $6.7 \mathrm{~m}$. The consideration of the panel width was based on trench stability and trench related impacts. In Kenny
Table 1: Summary the type of retention system selected

\begin{tabular}{|c|c|c|c|c|}
\hline Station & $\begin{array}{c}\text { Wall Type/ } \\
\text { Thickness (m) }\end{array}$ & $\begin{array}{c}\text { Excavation } \\
\text { Depth } \\
\text { (m) }\end{array}$ & $\begin{array}{c}\text { Wall } \\
\text { Depth of } \\
\text { Excavation } \\
(\mathbf{m} \text { bgl) }\end{array}$ & Remark \\
\hline KL Sentral & $\begin{array}{c}\text { D-wall } \\
1.2 \text { (Station box) } \\
0.8 \text { (Plant room) }\end{array}$ & $\begin{array}{c}21.5-25.2 \\
10.2 \text { (varies) }\end{array}$ & $\begin{array}{c}33.5-36.7 \\
17.5 \text { (varies) }\end{array}$ & Top-Down \\
\hline Pasar Seni & $\begin{array}{c}\text { D-wall } \\
0.8 \text { (Adit) } \\
1.0 \text { (Station box) }\end{array}$ & $\begin{array}{l}9.3 \text { (varies) } \\
22.8-24.5\end{array}$ & $\begin{array}{c}19.2 \text { (varies) } \\
30.8-32.8\end{array}$ & $\begin{array}{c}\text { Semi Top } \\
\text { Down }\end{array}$ \\
\hline Merdeka & $\begin{array}{c}\text { SBP (Adit) } \\
0.88 @ 1.36 \mathrm{c} / \mathrm{c} \\
1.0 @ 1.6 \mathrm{c} / \mathrm{c} \\
\text { D-wall station } \\
1.2\end{array}$ & $\begin{array}{c}8.1 \text { (varies) } \\
16.1-17.5 \\
31.1\end{array}$ & $\begin{array}{l}11.4 \text { (varies) } \\
20.1-28.6 \\
39.0-51.5\end{array}$ & Bottom up \\
\hline \begin{tabular}{|l|} 
Bukit \\
Bintang \\
\end{tabular} & $\begin{array}{c}\text { D-wall } \\
1.2 \\
\end{array}$ & 33.5 & $49-53.5$ & Top Down \\
\hline $\begin{array}{l}\text { Pasar } \\
\text { Rakyat }\end{array}$ & $\begin{array}{c}\text { SBP } \\
0.88 @ 1.5 \mathrm{c} / \mathrm{c} \\
1.18 @ 1.8 \mathrm{c} / \mathrm{c} \\
1.18 \& 1.5 @ \\
1.9 \mathrm{c} / \mathrm{c}\end{array}$ & 44.5 & $\begin{array}{c}\text { Rock levels bgl } \\
\leq 8 \mathrm{~m} \\
\leq 12 \mathrm{~m} \\
\leq 23 \mathrm{~m}\end{array}$ & Bottom up \\
\hline Cochrane & $\begin{array}{c}\text { SBP } \\
0.88 @ 1.5 \mathrm{c} / \mathrm{c} \\
1.0 @ 1.6 \mathrm{c} / \mathrm{c}\end{array}$ & 32 & $\begin{array}{l}\text { Rock levels bgl } \\
\leq 8 \mathrm{~m} \text { to } 10 \mathrm{~m} \\
\leq 10 \mathrm{~m} \text { to } 15 \mathrm{~m}\end{array}$ & Bottom up \\
\hline Maluri & $\begin{array}{c}\text { SBP } \\
1.0 @ 1.6 \mathrm{c} / \mathrm{c} \\
1.5 @ 2.4 \mathrm{c} / \mathrm{c} \\
\end{array}$ & 24 & $\begin{array}{l}\text { Rock levels bgl } \\
\leq 10 \mathrm{~m} \text { to } 15 \mathrm{~m} \\
\leq 16 \mathrm{~m}\end{array}$ & Bottom up \\
\hline
\end{tabular}

Hill Formation where the soil is competent, wide panel widths are preferred, caveat on other considerations such site constraints, logistic related to concrete supply, high capacity cranes required to handle the steel cage, etc.

iii. D-wall excavation system - There are several D-wall excavation systems that can be used depending on the soil condition, construction program, machine and experienced operators' availability. Some of the D- wall system includes mechanical grabs, hydraulics grabs and rotary cutters. For this KVMRT project, hydraulic grabs were used to depths of $30 \mathrm{~m}$ and in hard material with SPT $>50$, the reverse circulation 'Trench Cutter' or 'Hydrofraise' rotary cutters were used (see Figure 6). These large machines kept the trenching time to a minimum while minimising noise and vibration and these machines are also equipped with adjustable flaps to ensure the required verticality.

Some of the challenges encountered during the construction of the D-walls include -

i. Verticality - D-wall verticality is crucial especially in load bearing D-walls or to preserve the kinematic envelope where there is space constraints and where tunnel bore through is expected. To ensure verticality, properly constructed guide wall and steering of the hyrofraise with the built-in flaps would have to be used to ensure the required tolerance of 1:200. For D walls constructed with mechanical or hydraulic grabs ultrasonic 'Koden' system was used to check the verticality of the completed D-wall.

ii. Trench Collapse - D-wall Trench collapse although not common in Kenny Hill formation can be minimised 
with suitable slurry mix, smaller bites and shortening the trenching time. For Kenny hill, sometimes the contractor can underestimate the amount of fine Silt content generated and any impediment to the efficiency of the hydrocyclones to separate sand and silt from the bentonite may affect the quality of the treated bentonite and possible trench instability/quality of the concrete.

iii. Obstruction and planning - During the project, there were numerous obstructions and challenges to D-walling works, for example, limited headroom due to existing viaduct structure (see Figure 6), existing structures/piles/basement slabs (see Figure 7), abandoned ground anchors, in situ utilities (e.g. 132kV TNB cables) and etc. The D-walling rigs and supporting cranes used were so heavy; that they required proper foundation or ground improvement works for the temporary working platform. It must be stressed that these challenges must be properly identified and planned in advanced as part and parcel of good D-walling practice.

\subsubsection{Performance of Deep Excavations in Kenny Hill}

Tan et al., (2015) reported that in general, all the deep excavations in Kenny Hill perform better than expected where the deformation and struct loads measured were less than the predicted design values. As an example, the performance of the excavation works for Merdeka Station is presented below. The site investigation and the subsurface condition is present in Figures $8 \mathrm{a}$ and $8 \mathrm{~b}$. Figure 9 is a progress photo of Merdeka D-wall retention system with an excavation depth of more than $31 \mathrm{~m}$ below existing ground level. The performance of the stages of construction works were monitored by 12 numbers of in-wall inclinometers and at least 18 numbers of load cells and vibrating wire strain gauges for monitoring the strut loads. Figure 10 shows the Inclinometer INW2 monitored movements in the D-wall panel over a period of more than one year during excavation and compared with the overall design prediction displacement envelope. In general, the monitored movements were well within the design envelope at the critical sections while some deviations were observed at the top of the D- wall.

In summary, the deflection profile of the walls (see Figure 10) and the Strut loads (see Table 2) as shown by the monitoring

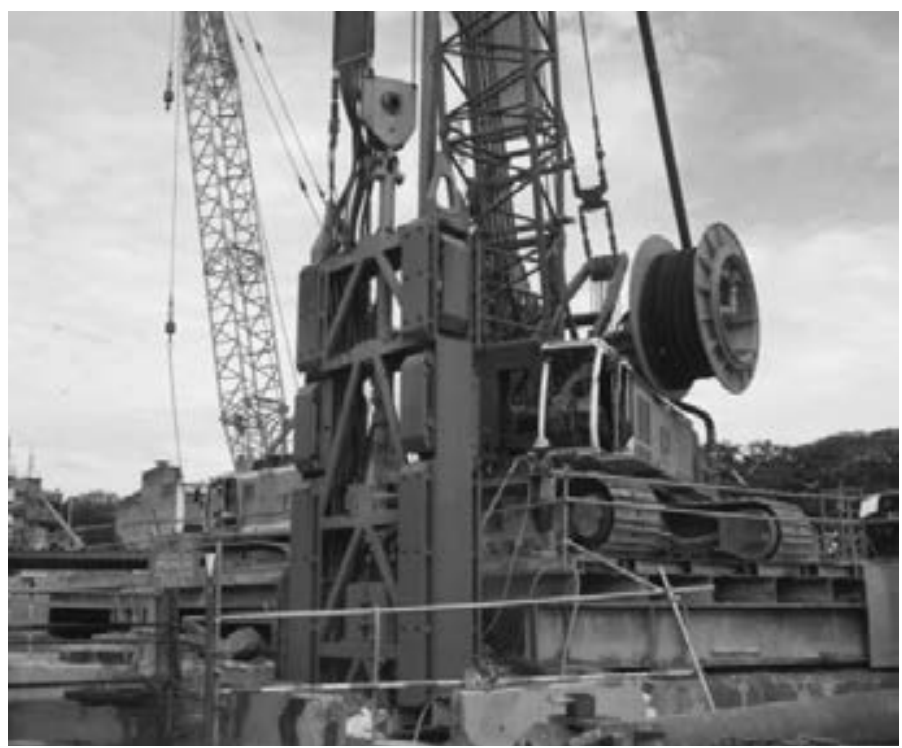

Figure 5: 'Trench Cutter' D-wall machine at Pasar Seni Station sitting on Temporary platform

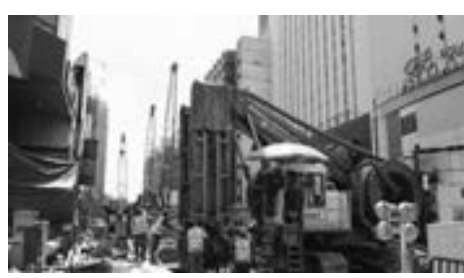

Figure 6: Low Headroom

'Hydrofraise' D-wall machine at Bukit Bintang Station

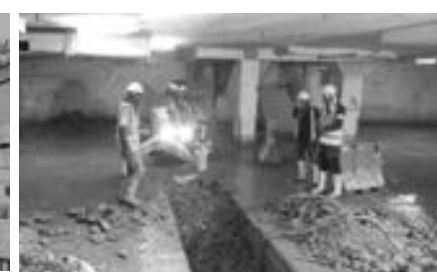

Figure 7: Pre-cutting of existing basement slab, to enable D-wall work to proceed at Pasar Seni Station results had demonstrated that D-wall retention system had performed satisfactory within the design prediction, hence, negligible impacts to Stadium Negara, schools and buildings adjacent to the excavation.

\subsection{MANAGING DEEP EXCAVATION WORKS IN KARSTS}

Diaphragm walls are not commonly adopted as the retention system in limestone due to construction challenges posed by the highly variable bedrock profile resulting in the risk of inadequate toe restraint as well "incomplete" panel excavation. The more recent use of trench cutter may remove the risk of keying into rock but the risk of trench collapse due to the loss of slurry when cavities or high permeability zones are encountered (especially for larger panel widths of about $6 \mathrm{~m}$ ). The sudden loss of slurries may result in the collapse of the slurry trench wall leading to the loss of ground supporting the heavy D wall rigs posing high risks to the $\mathrm{D}$ walling operation and impact to surrounding structures. In the event D wall system is to be adopted in karst, it is imperative to carry out comprehensive site investigation and ground treatment works before the commencement of D walling works. Adequate storage of bentonite and contingencies measures should be in place to handle slurry loss. In the event of sudden loss of slurry to undetected and untreated solution channels, the excavated muck is normally used for backfilling the trench in order to ensure temporary trench wall stability. To complete the $\mathrm{D}$ wall to the depths required may involve sequential back filling

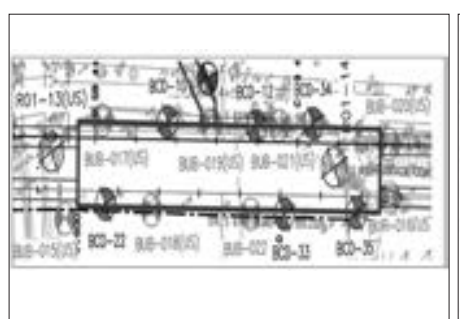

Figure 8a: Merdeka station borehole layout

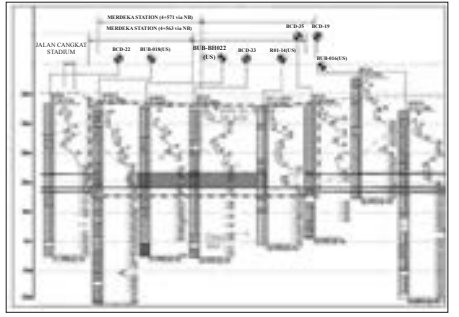

Figure 8b: Merdeka station simplified subsurface profile

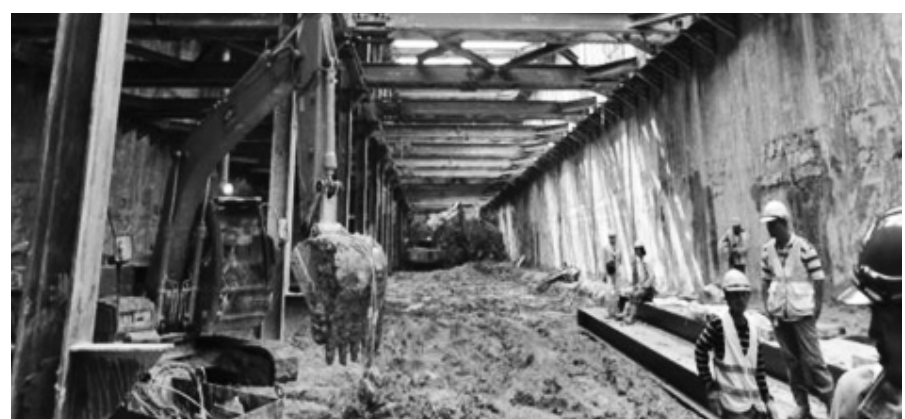

Figure 9: Bottom up excavation in Kenny Hill formation at the Merdeka Station 


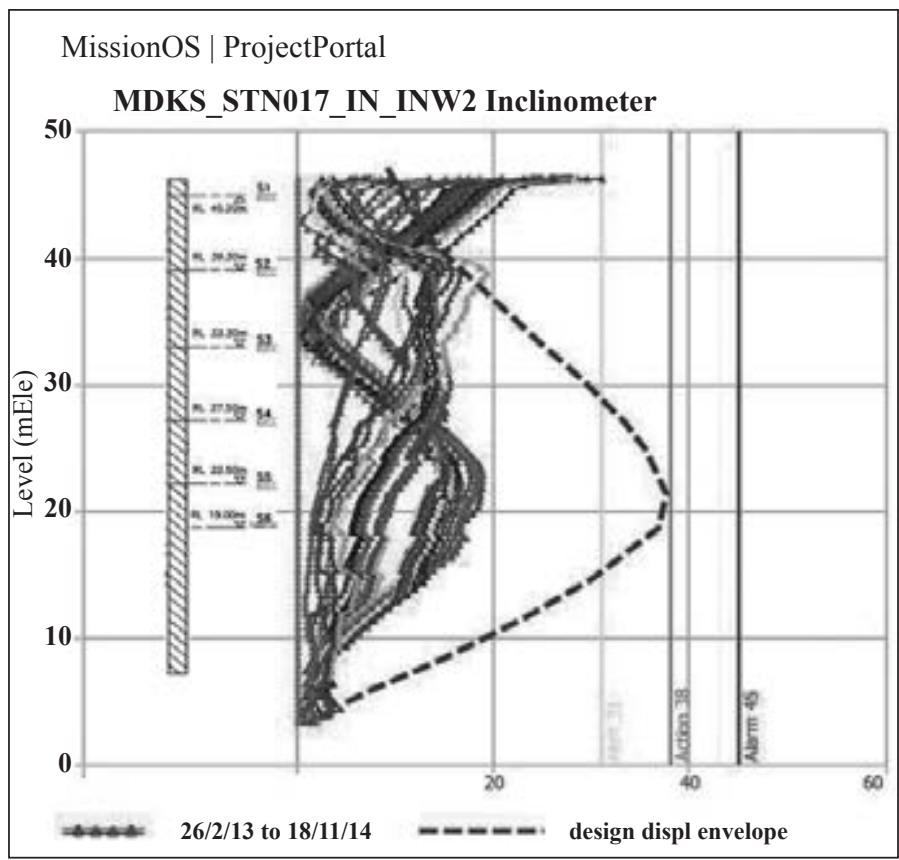

Figure 10: Inclinometer INW2 in Merdeka D-wall panel taken from the project online data management system Maxwell Geosystems

Table 2: Strut loads as monitored versus the design prediction

\begin{tabular}{|l|c|c|}
\hline Struts & $\begin{array}{c}\text { Design } \\
(\mathbf{k N} / \mathbf{m})\end{array}$ & $\begin{array}{c}\text { Measured } \\
\mathbf{( k N / m )}\end{array}$ \\
\hline S1 & 560 & 125 \\
\hline S2 & 1250 & 430 \\
\hline S3 & 1780 & 791 \\
\hline S4 & 2380 & 768 \\
\hline S5 & 1680 & 569 \\
\hline S6 & 1070 & 367 \\
\hline
\end{tabular}

with mortar and re-excavating and in some cases pre-treatment may be necessary prior to $\mathrm{D}$ walling.

In view of the risks associated with $\mathrm{D}$ Wall construction in limestone, SBP wall was adopted for SBK line to retain the overburden soil or alluvium, the challenges in design and construction are discussed below:

i. $\quad$ Pile size - The typical pile size selected for the SBP wall design varies from 0.9 to $1.5 \mathrm{~m}$. For construction ease and control the number of piles sizes used was limited.

ii. Overcut - The overcut needed was determined by the verticality tolerance of the pile (in this project 1:100) and the depth. Because it was designed as a temporary wall, overcut of 0.1 to $0.2 \mathrm{~m}$ (controlled by guide wall, see Figure 11a) was generally sufficient for short wall of up to $12 \mathrm{~m}$ depth.

iii. Steel content- Normally the amount of steel content for SBP is control by the spacing of the male piles (see Figure $11 b)$, the depth of excavation and the ground anchors spacing. For some of the station, like Pasar Rakyat, the typical steel content for the male reinforced pile was between $2.5-3 \%$. It may be prudent to have a range of piles (for a given diameter) with different capacities by varying the steel content to cater for the high variation in pile length over short distances. iv. Rock socket - The SBP piles were designed to be 'toe in' 'competent rock' in the absence of suitable rational guidelines on the definition of competent rock, Point Load Index values was used in consultation with the consultant and specialist contractors.

v. Karst conditions - Localised solution channels and cavities were sometimes encountered during the drilling works. The specialist sub-contractors deployed high torque rigs and fully cased drilling method to minimise the collapse of drill holes and down time due to these conditions. In addition, the sequences of drilling for these piles was arranged so that no drilling was carried out next to newly concreted piles.

vi. Ground anchors/struts - Where space is available, temporary ground anchors were preferred to struts to provide an obstruction free excavation (see Figure 12). The spacing of the ground anchors was designed to ensure good progress of excavation in mind with minimal impact on the excavation and ground anchor installation cycle times. Generally, the spacing used ranges from $2.5 \mathrm{~m}$ to $3.5 \mathrm{~m}$.

From Figure 13 it can be seen that the SBP wall is not extended below the final excavation level. Hence, curtain grouting cut-off was provided along the perimeter to cut off seepage of water and solution channels. The depth of grout curtains adopted was $10 \mathrm{~m}$ below the final excavation level and the spacing of the fissured grouted curtain varies from $1 \mathrm{~m}$ to $4 \mathrm{~m}$ with the acceptance performance criteria of the curtain grouting set at 5 Lugeons or lesser.

Since the SBP structural retention system did not extend below the final excavation level. Under such circumstances rock excavation by controlled blasting was normally carried out to the final excavation level. The blasting works must be controlled to an acceptable peak particle velocity to ensure that the integrity of the surrounding buildings and the soil retaining wall is not compromised. The exposed excavated rock face and base is vulnerable to seepage flows when solution channels and cavities are connected to the surrounding ground water table. Ideally, it would be ideal to extend the structural retaining wall all the way below the final excavation level to provide adequate seepage "cut-off". The above condition was not feasible due to great depths of rock excavation and the constraints on the availability of suitable machines capable of drilling or cutting to such depths and have the construction accuracy to maintain the desired interlock or "cut-off" expected. It was also not possible to procure sufficient number of competent specialists to carry out the works to meet the quality, construction time and schedule. As a result, often, several methods to provide retention/ cut-off were designed and subsequently selected to suit the site

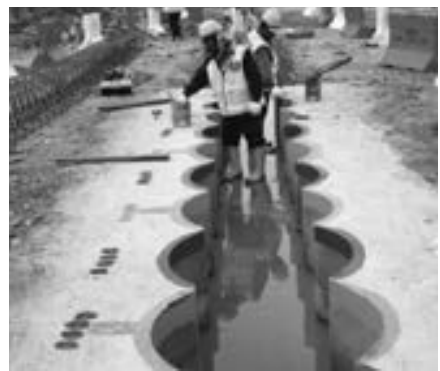

Figure 11a: SBP guide wall being prepared prior to drilling works

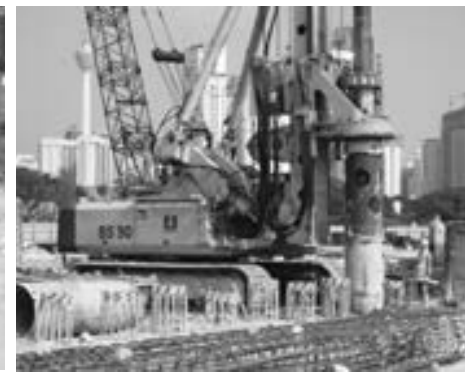

Figure 11b: Secant bored piles wall installation and reinforcement of 'male' piles 


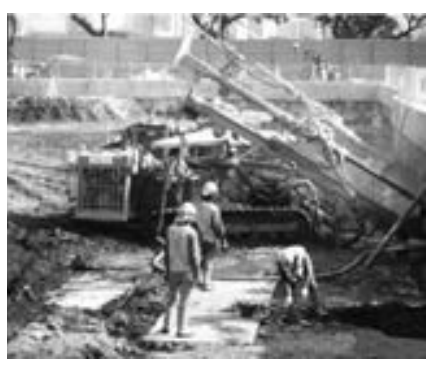

Figure 12: Installation of Temporary Ground Anchors for the SBP wall

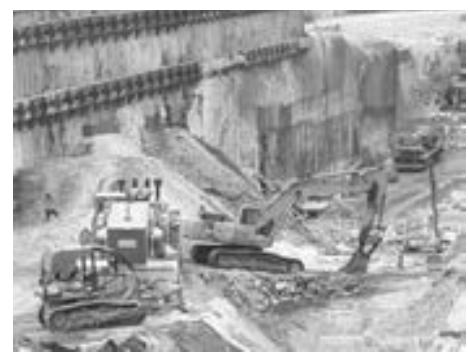

Figure 13: Excavation works at Pasar Rakyat in rock showing - Combination of Drill \& Blasts method and Surface Miner condition and to utilise the entire fleet of available specialist subcontractor to minimise overall program risks.

The case history discussed below is based on SBP wall retention system in soil where further excavation in rock to depths ranging from 20 to more than 35 meters below the toe of the SBP piles.

In this case, grout curtain below the structural SBP wall was used in lieu of a structural "cut-off". Grout curtains are commonly used in dam projects to control seepage flows below the dam foundation to an acceptable level. In the same manner, this method was adopted to control the potential inflow of ground water from the limestone bedrock into the excavation pit. The curtain grouting was carried out to "refusal" based on the standard closure grouting method. The grouting started with primary grout holes followed by secondary, tertiary and quaternary grout holes where required until "refusal" at the "final" grout hole (the grouting sequence is shown in Figure 14). The termination criteria for grout holes that has high grout consumption was based on a certain grout take limit and the quantity/volume specified is based on the experience of the designer (e.g. $1 \mathrm{~m}^{3}$ per metre grout section). It must be highlighted that proper drilling records reflecting the subsurface response to drilling must be reported. Information such as air or water loss, presence of cavity infilled or otherwise must be carefully recorded. The locations where solution channels were encountered must be carefully monitored during grouting. Based on the current experience, the drilling records need further improvement. However, the grout consumption records provide very good information of potential zones of high seepage related problems. The locations with high grout takes are likely to be locations where solution features or fracture zones were present.

Figures 15 and 16 show the borehole layout and typical subsurface profile for Cochrane and Pasar Rakyat station respectively. The overall grout take for the two station shafts were plotted with depth on the rolled-out elevation in Figures 17 and 18. From the two figures it was obvious that shaft Pasar Rakyat has higher overall grout consumption and has many more locations with high grout takes even though both shafts have been treated to the same refusal criteria. During excavation Cochrane was observed to be relatively tight with less seepage problems. Pasar Rakyat shaft on the other hand has many locations with quite high in flow of groundwater.

It appears that the frequency of seepage encountered during excavation was highly correlated to grout take during curtain grouting. The locations of seepage and intensity of seepage flows during construction was also found to be correlated to grout consumption.
In theory grout curtain, should work, but in karst the efficiency of this treatment system was highly dependent on the successful treatment of all possible solution or interconnected seepage channels which was not practical. Figure 19 shows the case of high water inflow through a localised open join surrounded by massive limestone with tight joints. It was highly unlikely that such features can be detected upfront and exact treatment from the ground surface was nearly impossible. Furthermore, the damage or aggravation of the treated solution channels from blasting is difficult to quantify. In order to minimise the effects of blasting, the curtain grouting was carried out at about $5 \mathrm{~m}$ away from the excavation face.

Therefore, mitigation measures to address seepage flow during excavation was factored in as part of the ongoing treatment works in tandem with the excavation works. Advance grouting works where required was carried out to prevent excessive inflow with every blast cycle. In the same manner, at locations where the advance curtain grouting failed to cut-off the seepage flow during excavation (may it be solution channels, fractured zones, etc.), additional grouting would be required and the grouting was best carried out from the ground level and from the excavated platform to treat the solution channels curbing the source of seepage. In view of the high head with

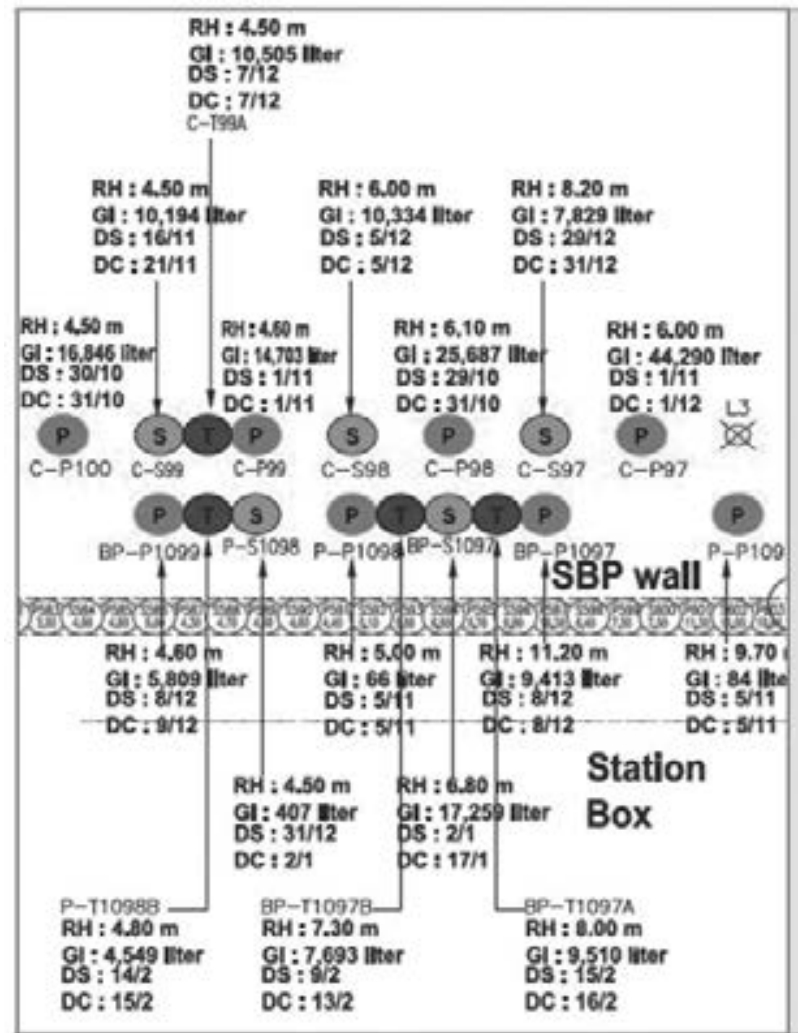

Figure 14: Typical curtain grouting drawing and the notations are as follow; ' $P$ ' - primary points, 'S' - secondary points, ' $T$ ' - tertiary points, ' $\mathrm{RH}$ ' - depth to rock, 'GI' - grout intake, 'DS'-date started, 'DC'- date completed and ' $L$ ' denotes Lugeon tests

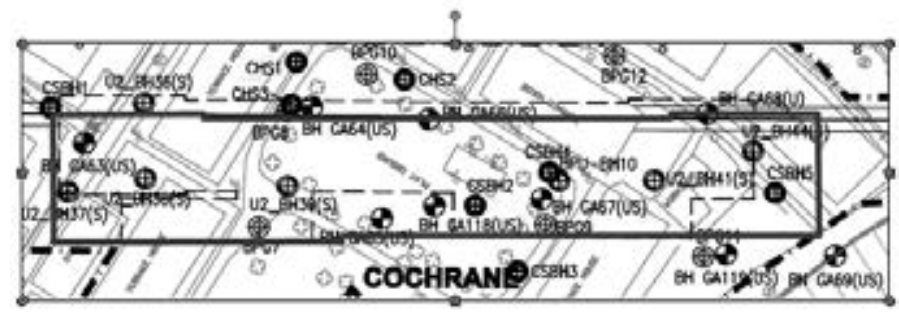

Figure 15a: Cochrane Station borehole layout 


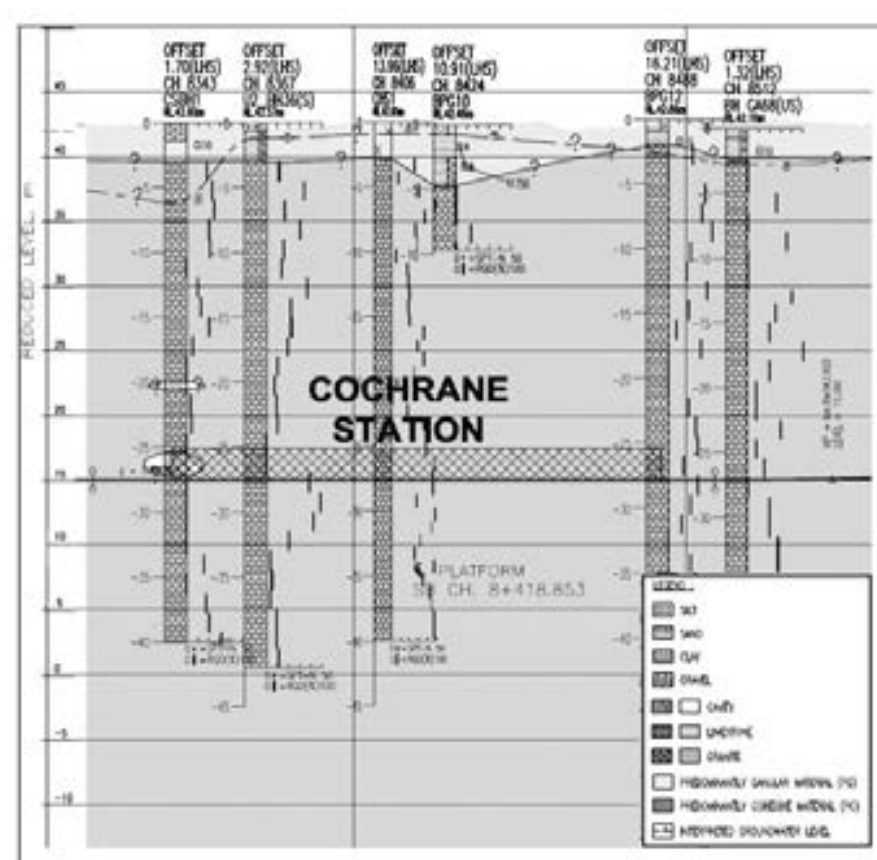

Figure 15b: Cochrane simplified subsurface profile

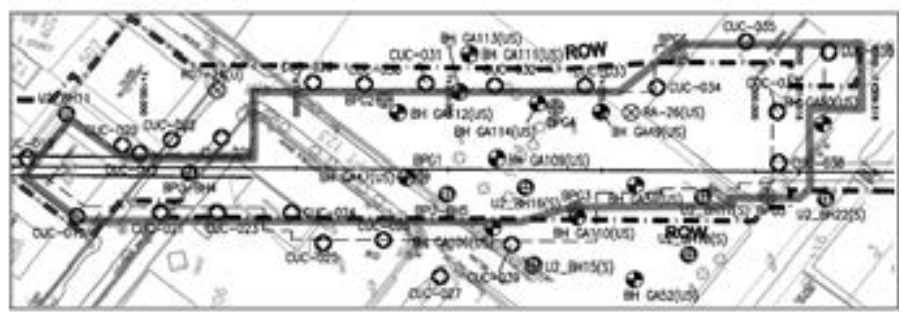

Figure 16a: Pasar Rakyat Station borehole layout

depths, the grout treatment process can be very challenging and many attempts and combination of grouting methods were required to mitigate the seepage. However, major seepage should be addressed quickly failing which it could result in sinkholes and subsidence as well as potential building damage.

It was observed that installation of ground anchors was also one of the sources of seepage and ground settlement. The method of advancing the borehole had an impact on settlement and formation of sinkholes when the installation intersected solution channels. In order to minimise such impacts, the anchors was installed using casing drill and in some cases pre-treatment was required in sandy and poor ground conditions.

Despite the many challenges faced during deep excavations and in particular in KL limestone, the stations (see Figure 20) were completed on time for sectional handover and completed and opened to the public on time and cost with minimal impact to the public.

From the feedback and I\&M monitoring results, we can conclude that the KVMRT retention systems have complied and met their design objectives. With the extensive instrumentation and monitoring invested in place within the current retention systems, it would be possible to further improve on the design for a more robust and efficient retention systems in the future.

\subsection{MANAGING DEEP EXCAVATION RISKS}

Risk management is an important process to ensure safe and timely delivery of a project. Deep excavation can be a laborious process and may be subjected to many constraints

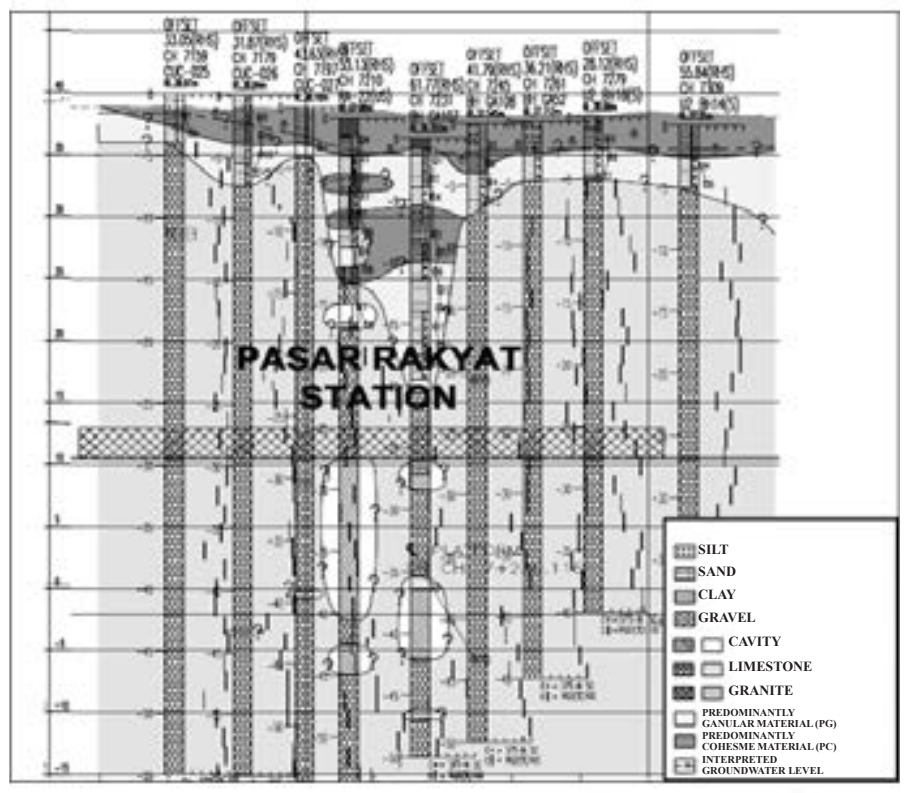

Figure 16b: Pasar Rakyat simplified subsurface profile

and requirements. The logistics of moving out of excavated spoils, environmental control, restricted working hours in urban environment, getting approved dump sites and advance relocation of utilities are activities that can contribute to program risks. Hence, it can be appreciated that at the initial stages, the risks are mainly related to design matters, land issues, approvals, relocation of utilities and third party engagement.

The quality and sufficiency of information obtained for design determines the level of the design risks. Hence, designers would like to have an accurate subsurface model and associated design parameters. Information such as permeability of the site with depth and the impact of ground water conditions would be essential for geotechnical designs of deep excavation works.

As the work commences, construction related risks becomes more apparent as well as the risk of impacts to the surrounding buildings. In general, the risks could be broadly related to the following; collapse of soil retention system, collapse of rock face during excavation, excessive seepage due to undetected/ untreated solution features, excessive draw down in groundwater regime, settlement of surrounding buildings and the potential development of sinkholes even at locations outside the perceived zone of influence.

Such unforeseen incidences could be attributed to the high hydraulic heads caused by the deep excavation and the dewatering
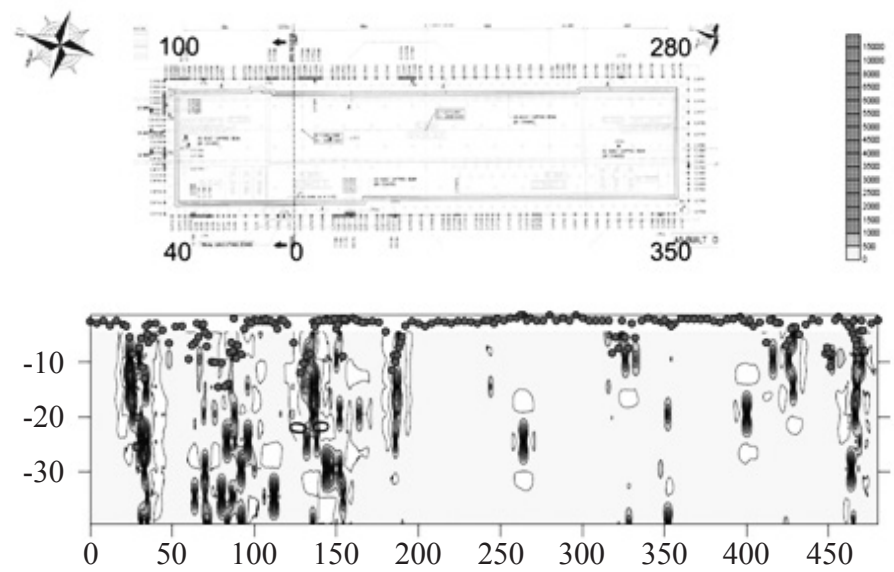

Figure 17: Elevation of grout take with depth for Cochrane Station 
being carried out to maintain a relatively dry working platform. In the event the excavation works intersects some highly unfavourable and big diameter subsurface solution channels, it can lead to a sudden huge inflow of ground water. Prolonged flow and lethargy in deployment of treatment works can lead to sudden collapse of overburden soil resulting in sinkholes. This phenomenon occurs when the soil arch is breached due to the loss of overburden soil at the soil/rock interface into pre-existing voids within the limestone bedrock. This class of sinkholes have been reported to take place at locations of hundreds of metres away from the source of seepage in the excavation pit.

This paper has presented some of measures and rationale of mitigating ground water inflow into excavation in karst. In order to appreciate the monumental task of "tanking" in-situ limestone bedrock, we need to take an honest look at the efficacy of a purpose designed and "treated" water retaining basement wall structure. It can be appreciated that at the moment dewatering stops after the completion of the basement structure, the water level behind the wall builds up. During this process, the groundwater will find all the flaws in the engineered retaining wall and manifest in wet patches and ground water seepage flow. The severity of the problem does not rest solely on the structural defects but also on the permeability of the retained ground. There are many cases where after many attempts of repair/sealing, a pragmatic solution to the problem involves a skin wall with scupper drain. This is because after several attempts of expensive sealing, one

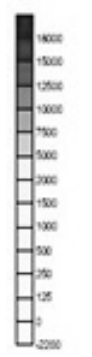

PASAR RAKYAT STATION
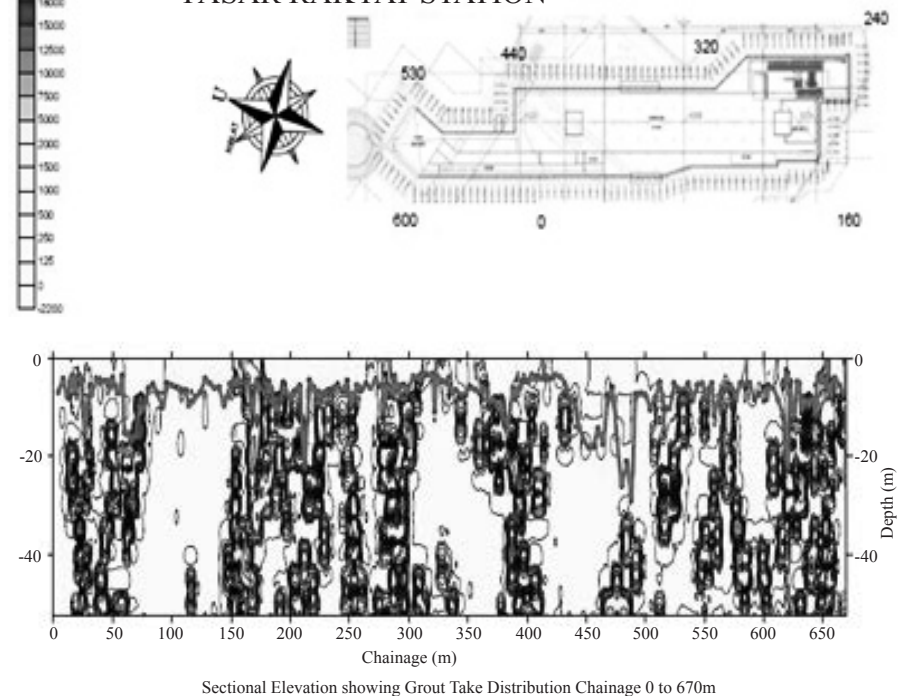

Figure 18: Elevation of grout take with depth for Pasar Rakyat

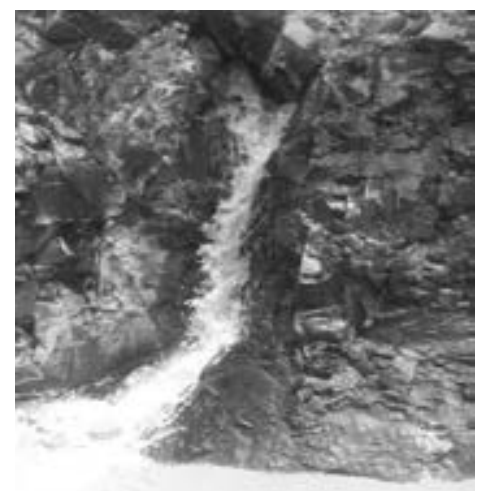

Figure 19: High seepage flows through localised open joint (surrounded by massive limestone with tight joints) that has eluded treatment

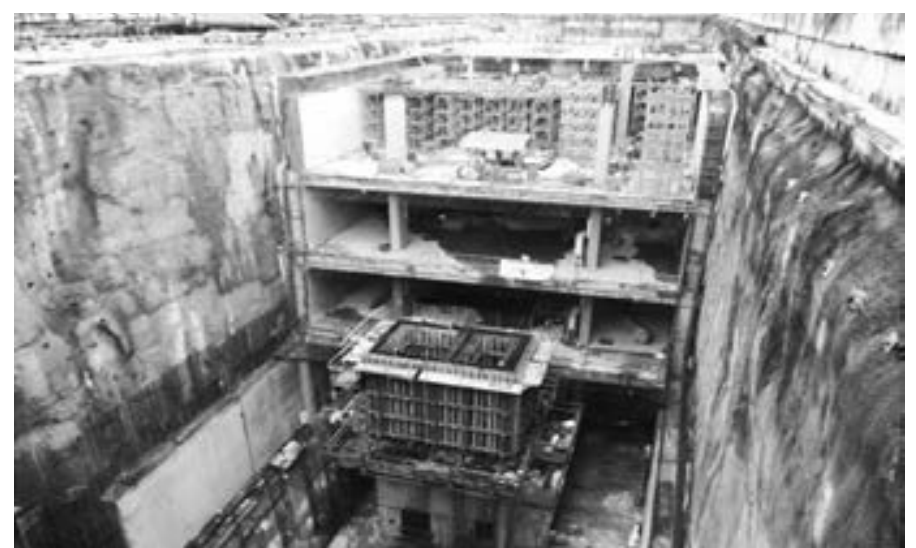

Figure 20: Partially completed Cochrane Station Box

then concedes that groundwater has the bad habit finding new points to leak when the current points have been sealed.

\subsection{MANAGING TUNNELING WORKS}

The indicators of good TBM tunnelling performance is probably good advance rates with minimal volume loss or surface settlements. Some of the parameters governing the performance are ground conditions and geology, type of TBM and capacity, muck conditioning and muck out system, logistic of segment delivery and material supply. Selecting the right TBM to match the geology, the rock type and its consequential weathered derivatives and the groundwater profile along the alignment will ensure good tunnelling performance. A simple chart showing the relationship between soil granulometry and type of TBM is shown in Figure 21.

In a broad sense, EPB methods are suitable for fine grain or cohesive soils while Mixshield or slurry methods on other hand are more suitable for granular soils like Sands and Gravels.

The challenges of tunnelling generally relate to unfavourable geology or subsurface conditions that can lead to a sudden inflow of groundwater, loss of face support pressure, leakages or escape of pressurised slurry or air to the surface, the obstruction to tunnelling by man-made structures, the close proximity of utilities and structures. The following presents the selection of TBM, performance of TBM tunnelling in Kenny Hill and Limestone Formations and some specific challenges related to the project.

\subsubsection{Selection of TBM For SBK Line}

In general, the TBM is broadly selected to suit the ground/ geological and hydrogeological condition of the alignment but treatment or conditioning of the soil maybe required to ensure good face support and efficiency of tunnelling. From the geology, the subsurface condition of the ground and the groundwater profile along the tunnel drive, it was apparent that earth pressure balancing (EPB) TBM with soil conditioning was ideal for the residual soils of Kenny Hill Formation (see Figure 22). However, for buried karst with a high ground water table, the selection of the right TBM with the capability to handle the variable rock head, cavities and solution features is of paramount importance. In the past mixed shield/ slurry TBM was adopted for the SMART project and the current SBK line adopted the innovative variable density (VD) TBM that can operate in 


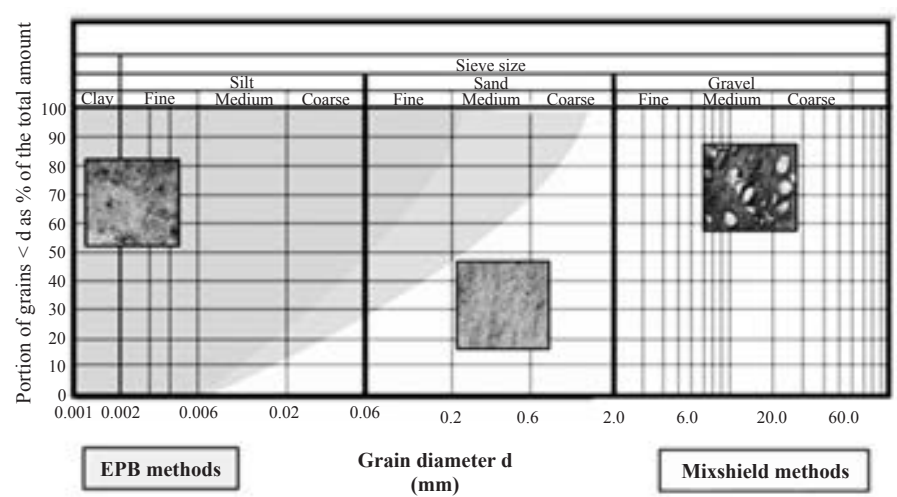

Figure 21: Simplified chart showing TBM type versus soil type

multi-mode (see Figure 23). The innovative VD TBM was the result of the research and collaborative works of MGKT, Herrenknecht AG and Ruhr University. This versatile TBM that can operate in four different modes from pure EPB mode to high density mixshield mode "at the flip of a switch" during tunnelling to deal with the variation or changes in geological and hydrogeological conditions. The versatile VD TBM was developed to overcome the shortcomings of the Mixshield/slurry TBM experienced during the SMART project. These problems relate to the intersection of solution channels during tunneling. This may results in the escape of slurry to the surface ("blow outs") or sinkholes when there is loss of face support pressure. The development of the VD TBM, the high-density slurry mixes (ranging from 13 to $17 \mathrm{kN} / \mathrm{m}^{3}$ ) and the performance of this TBM unique features have been reported by Klados et al., (2015).

\subsubsection{EPB tunnelling in Kenny Hill Formation}

The residual soils of Kenny Hill Formation was conducive for EPB tunnelling with foam and water as the condition agent at the cutting face and excavation chamber. High penetration of more than $20 \mathrm{~mm} / \mathrm{rev}$ and advance rate of more $9 \mathrm{~m} /$ day with a maximum production of $19.6 \mathrm{~m} /$ day were reported by Chin et

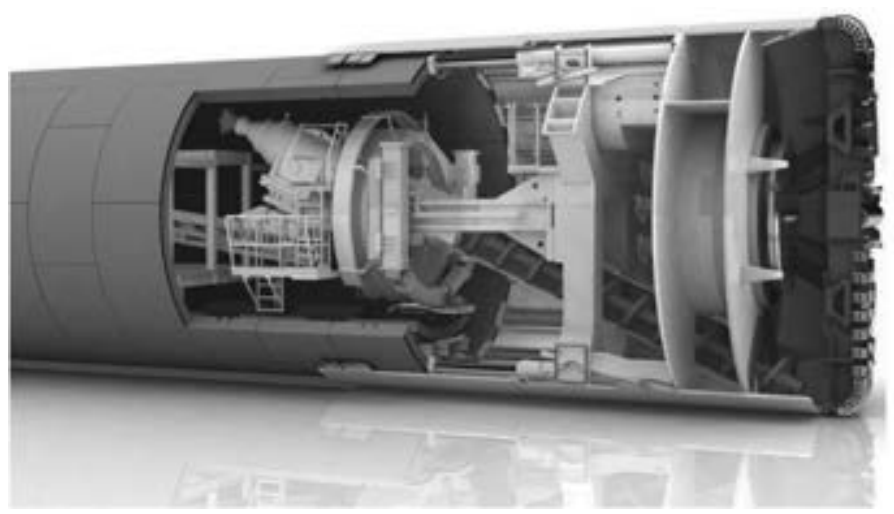

Figure 22: Earth Pressure Balance tunnel boring machine

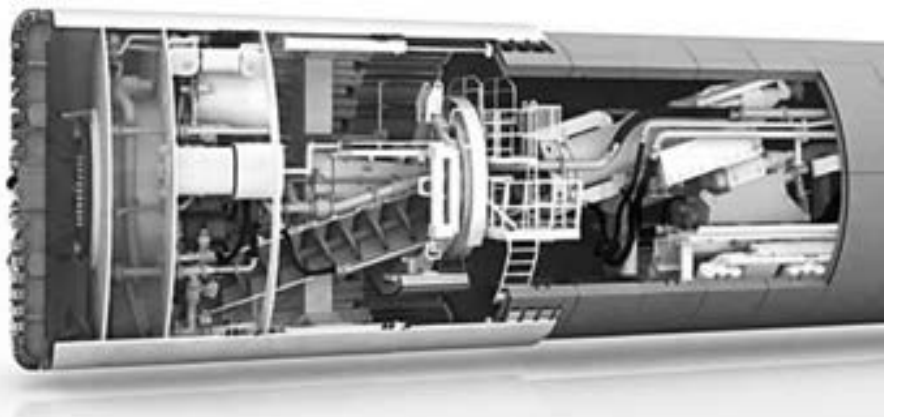

Figure 23: Variable density TBM

al., (2015). He also commented that with good face support and adequate annulus grouting, the surface settlement measured were typically between 3 to $17 \mathrm{~mm}$ corresponding to volume loss of 0.2 to $0.7 \%$. Although tunnelling through Kenny Hill formation was relatively benign it was not all smooth sailing. The tunnelling did encounter a stretch of very abrasive and strong quartzite of some 20 to $25 \mathrm{~m}$. The gauge and cuter discs were badly worn off and had to be replaced with hard rock type cutter disc. This was then followed with more frequent intervention to ensure acceptable cutter disc condition and replaced when required. Once the TBM

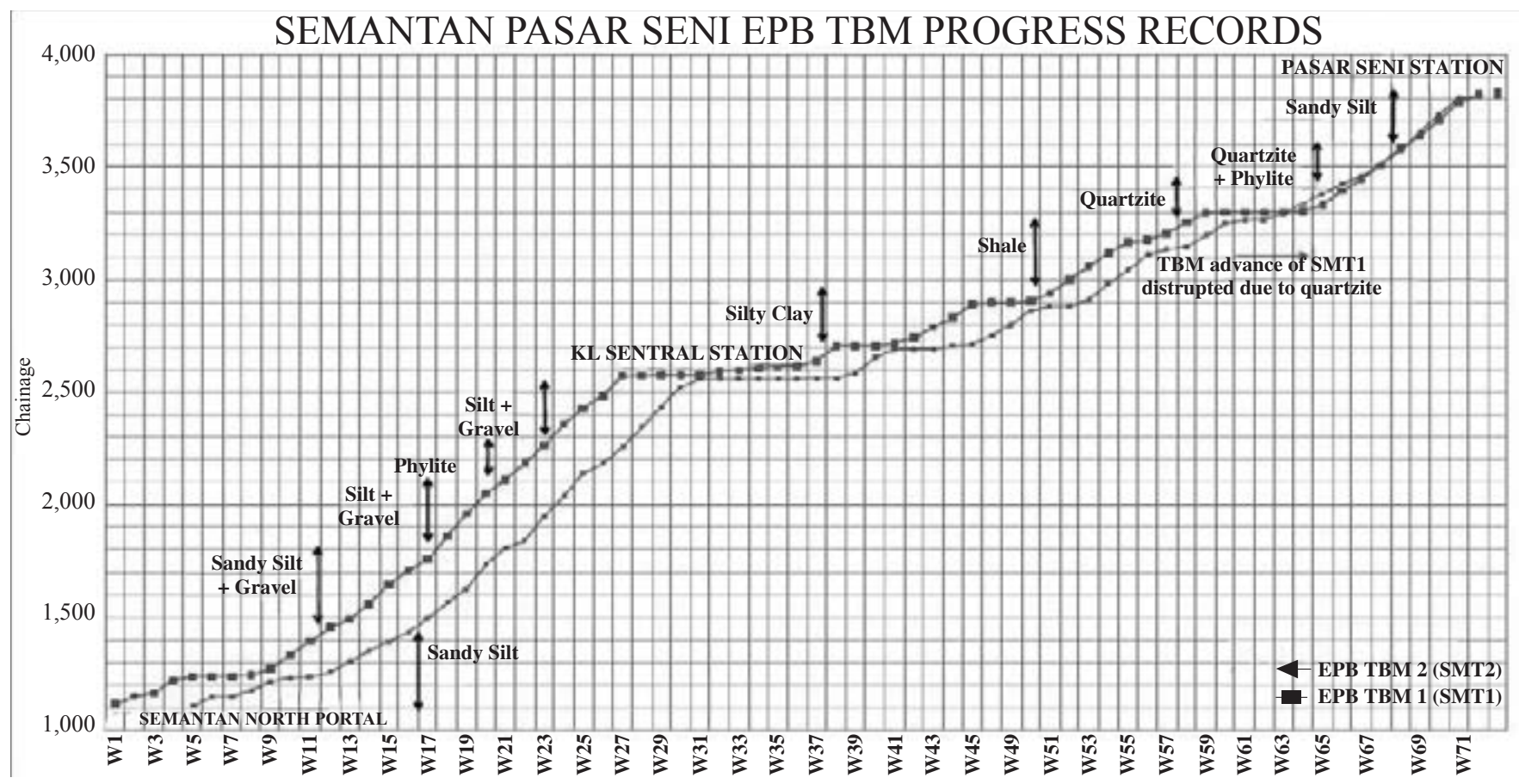

Figure 24: EPB TBM tunnel progress record (after Chin et al., 2015) 
has gone pass the quartzite rock, tunnelling was back to normal and the TBM progress between Semantan and Pasar Seni is presented in Figure 24. In general, TBM tunnelling in Kenny Hill formation was successfully completed with good face pressure control and minimal impact to structures and utilities along the tunnel drives.

\subsubsection{VD Tunnelling in Kuala Lumpur Limestone}

Firstly, it has to be appreciated when it comes to tunnelling in Kuala Lumpur karst it is not all science but it is really partly an art because one has to deal with more unknowns than what one can possibly identify. The science is related to the factual information and the art is how to use this information to complement the judgement factor that calls on the experience, local knowledge and understanding of the peculiarities related to KL Limestone.

The unfavourable conditions related to tunnelling in Kuala Lumpur karst could be the interbedded Sand and weak slime lenses in mine tailings, or interconnected cavities that are filled with either soil or slurry. Figure 25 shows the varying sizes of cavities and solution channels that may be encountered during tunnelling in karst. Figure 26, is a section of geological profile where the borehole information and geophysical survey information from MASW and EI have been superimposed. This information was studied and additional investigation was carried out to verify the anomalies detected which could be solution features or highly inundated fractured zones (highlighted by bubbles).

In Figure 27, the anomalies were found to be inundated fracture zones, however tunnelling in mixed faced condition can be expected for this stretch. Tunnelling in mixed faced condition is the case where at the excavation face of two or more surface areas with significantly different material properties that may affect TBM operation. In karst, the mixed face could even occur within the bedrock due to cavities and these cavities could be in filled with soil or weak slurries. The mixed face condition, the presence of solution channels in the tunnel horizon and its potential connectivity three dimensionally and the presence of predominant joint sets and fractured zones may result in blocky rocks that may pose problems to TBM operation.

Klados et al., (2015) presented some case histories where the novel multi-mode VD TBM was used to mitigate some of the above karst anomalies. In general, five (5) VD machines were used for tunnelling in karst with two of the VD TBMs converted to full EPB mode underground (the conversion took less than one week). This took place in Kenny Hill Formation after tunnelling through the geological interface of Limestone and Kenny Hill. The tunnelling works in Kuala Lumpur limestone was successfully completed using VD TBM with significantly fewer incidents compared to the SMART project. This was attributed to the flexible VD TBM to address the variability encountered during tunnelling in karst.

\subsection{MANAGING IMPACTS OF TUNNNELING ON EXISTING UTILITIES}

The dynamic road widening and the installation of utilities over the years have resulted in a very poorly defined corridor of different utilities laid at different depths. In most cases utility detection would be carried out prior to underground works. Based on the current experience, the new Telco lines were quite easy to detect due to the presence of redundant ducts that can be
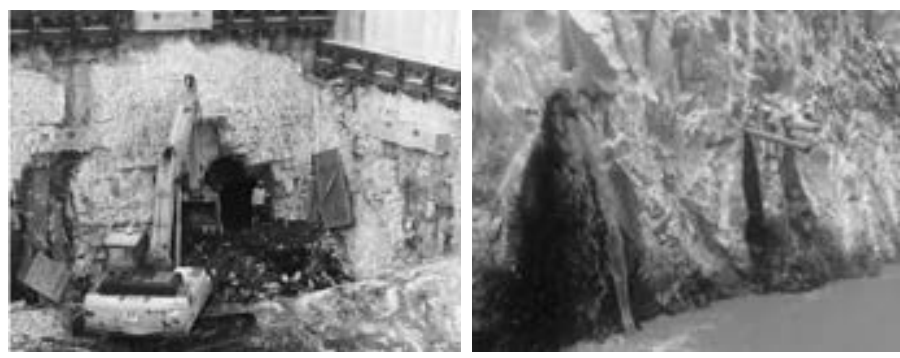

Figure 25: Photos showing sizes of cavity affecting TBM operation

used as access by sondes to map out the location and elevation of the lines. The detection of Tenaga Nasional Berhad (TNB) cables can be challenging because they exist in multiple layers, and generally the lower layers will be masked by the top layer of live cables detected. However these cables are relatively shallow when compared with tunnel depths and hence not directly affected by tunnelling. The indirect risks to TNB cables include burst water pipes and vibrations to some of the more sensitive oil filled power cables. Probably the most crucial utility related impact during tunnelling is the damage of water supply mains. The lack of good as-built drawings of the ailing old water supply pipes of asbestos cement and cast iron pipes that are still in service makes detection and mapping very difficult. The dilapidated condition of many of these pipes makes it highly susceptible to damage due to small changes in stresses, vibration and deformation induced by the tunnelling works. As a result, there were two "fairly major incidences" reported during tunnelling along Jalan Bukit Bintang due to the damage of old water mains. The first case of the water mains damaged occurred after some time lapse (ie the TBM has passed that location and damage took place later) and the repair was promptly completed, however a new damage took place at another location a short distance away. In the case of limestone formation with interconnected solution channels that are linked to overburden soils, the water from damaged water mains may trigger the formation of sinkholes when the overburden soils are washed into the voids or cavities. This was the likely mechanism of the "sinkholes" that occurred at the Jalan Bukit Bintang and Jalan Imbi Junction.

As a result of the above experience, the old water mains along Jalan Bukit Bintang were replaced. This proved to be a good decision as no further incidents related to burst water mains was reported during tunnelling and the commercial and tourist activities were preserved without incidences. In contrast, pipe bursts was quite common along this location during utility detection and implementation of localised ground treatment works.

\subsection{MANAGING THE IMPACTS OF TUNNNELING ON EXISTING STRUCTURES AND BUILDINGS}

In general, the alignment of most tunnels will follow existing roads and are expected to have minimal impacts on buildings and land acquisitions. In such cases, the impact on surrounding structures and buildings will be directly related to the settlement trough generated during tunnelling. The magnitude and size of the trough is generally related to depth, size of tunnel, the ground conditions and the volumetric loss during tunnel operations. In rock, the excavated tunnel should be self-supporting and little deformation on the overburden soils.

In the inevitable case where tunnelling was required to be carried out below existing building or structures then the 
risks related to tunnelling was evaluated on a case to case basis. Usually it is not feasible to carryout boreholes inside an occupied building with commercial activities. In order to circumvent the above problem and to obtain some information beneath the building, boreholes may be drilled outside the building and carry out cross-hole seismic tomography sections between the boreholes. This approach generates geological sections (tomograms) that can be interpreted for the presence of weak zones or solution features beneath the building. Where significant anomalous features are detected, advance ground treatment works may be carried out before TBM arrival. Figure 28 shows a plan and a cross-hole tomography section beneath a low-rise building, where a localised weak fractured zone was detected. Grouting works were proposed to treat the fractured zone identified in order to minimise any potential impact to the building during future tunnelling.

In order to have a better understanding of the impact of tunnelling on the building or structure it is necessary to know the type of foundation supporting the structures. Often, as built foundation drawings may not be available and in such cases, there is a need to carry out further investigation to determine the type of foundation system supporting the super structure. Trial pits were carried out to expose the foundation system whether it is shallow or deep foundations (see Figure 29). For shallow foundations, the impact on the structure may be evaluated based the method proposed by Burland and Wroth (1975) or Boscading and Cording (1989), where the green field settlement and the resultant tensile and shear strains were computed and classified in accordance to building damage categories. Appropriate protection measures were deliberated and agreed and put in place prior to tunnelling works.
In the case of deep foundation, excavation below the pile cap was carried out to determine the type of pile. Boreholes were then carried out next to the pile to determine the ground condition supporting the piles followed by parallel seismic survey to determine the pile length (see Figure 30). The same borehole may be used to detect the lightly depth of the pile using other geophysical methods such as magnetometry or borehole radar measurements. The inferred pile length was then used for clash analysis and also to evaluate the impact of tunnelling on the pile performance. It has to be noted that both parallel seismic method and borehole radar method is not effective in identifying the socketed section of the pile due to lack of contrast in stiffness between the pile and bedrock.

In the case where tunnelling was carried out at close proximity to pile supported structures, the loss in mobilised pile capacity may be estimated using the recommendation by Poulos and Deng (2004). In the case where the loss in capacity is compensated by pile settlement and load redistribution, these changes can be estimated using the charts published by Chen et al., (1999). Figure 31 shows the use of load transfer method to evaluate the redistribution of load in piles with depth caused by settlement induced by tunnelling was presented by Boon and Ooi (2016). More recently, the embedded pile 2D finite element method (FEM) is widely used, for a more rigorous analysis, model the entire tunnel construction sequence using 3D FEM. Once the risk has been fully evaluated, the actual response of the structure to the tunnelling works is carefully monitored and evaluated against the design prediction.

Figure 32 present a case where the some raked micropiles socketed in limestone that has encroached into the tunnel horizon. These piles were constructed with high tensile API pipes and the API pipes encroaching into the tunnel horizon had to be cut and removed prior to TBM arrival. Prior to pile cutting underpinning
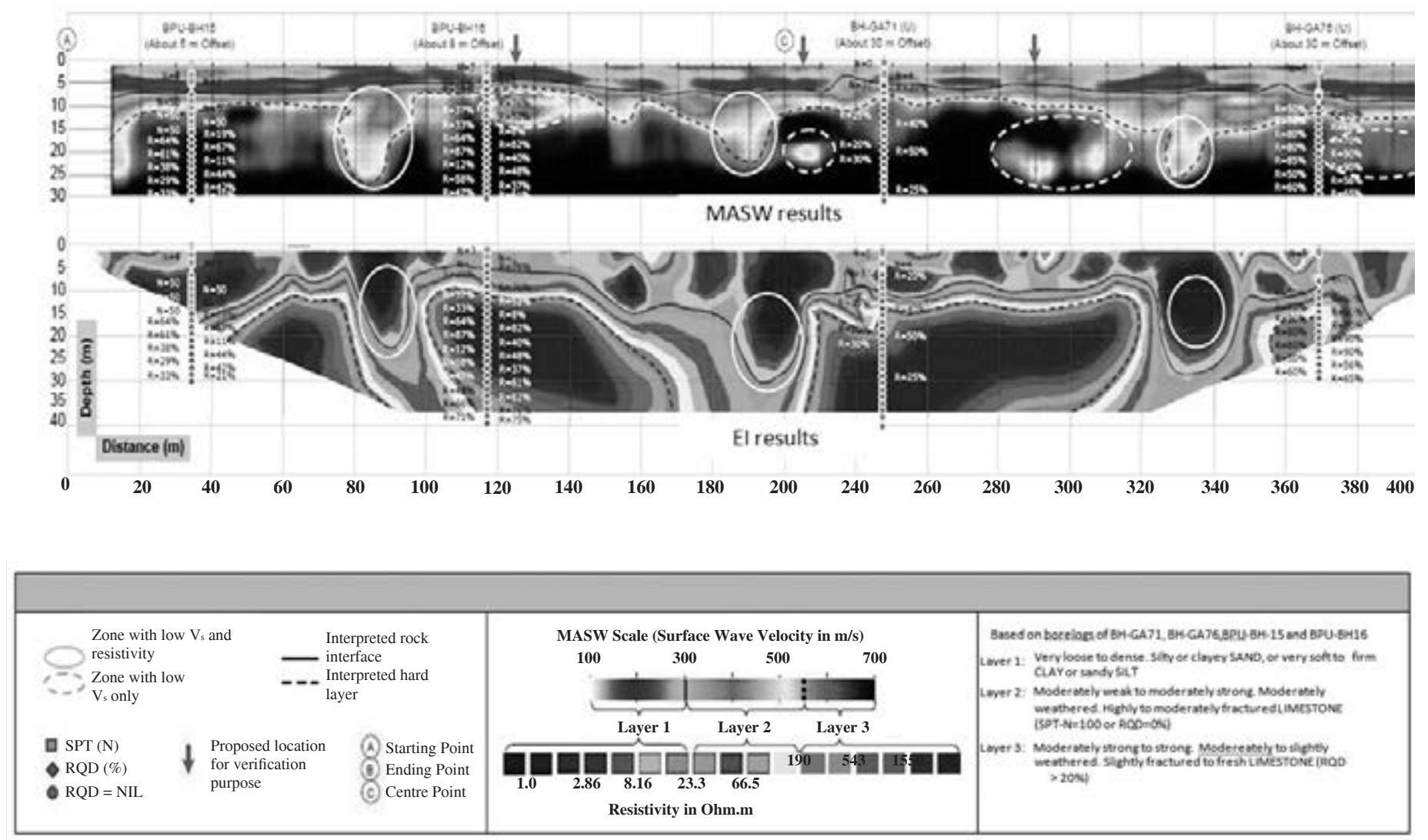

Figure 26: Geophysical survey image obtained from MASW and EI 


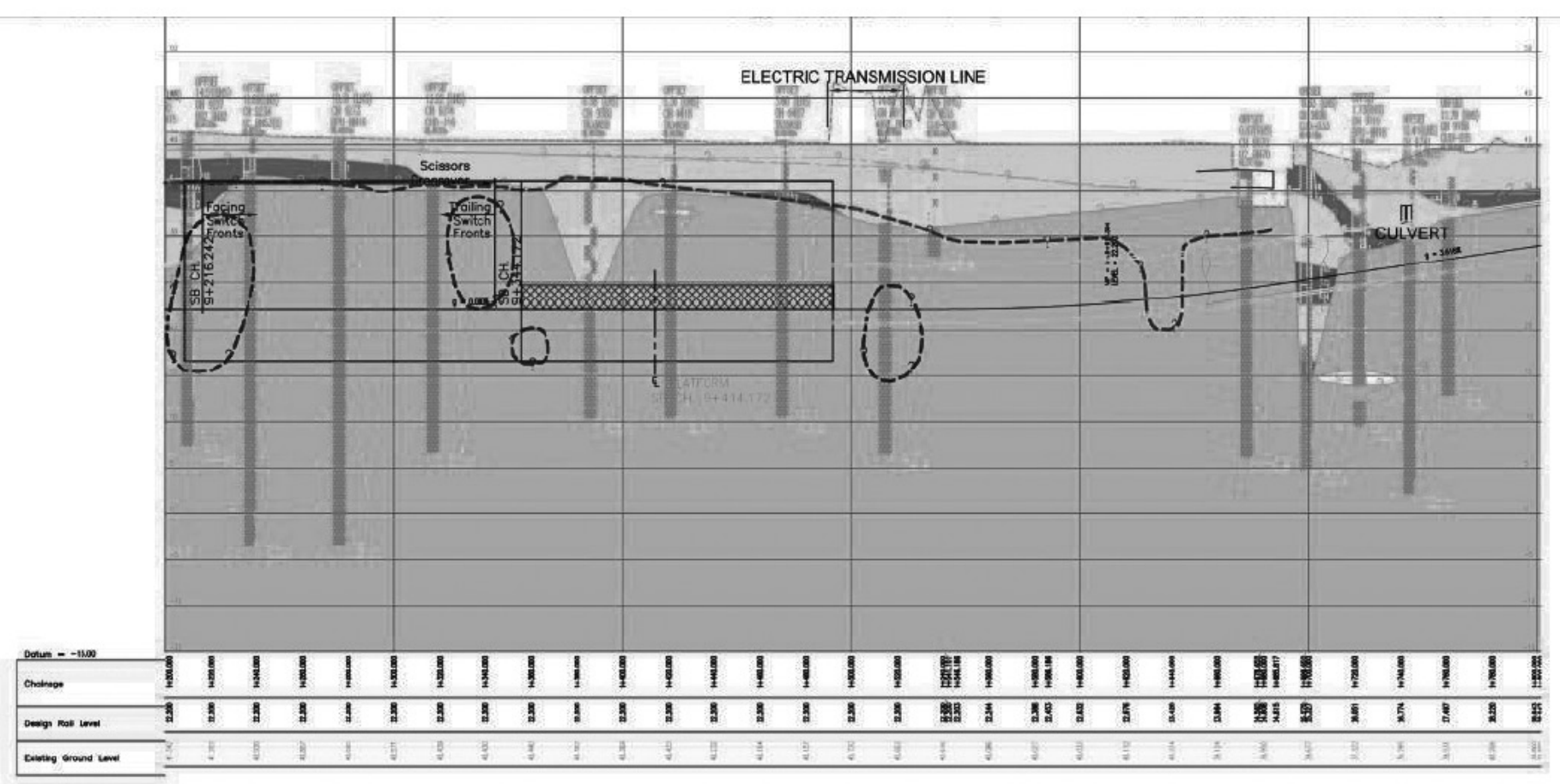

Figure 27: Combined plots of MASW, EI and additional verification boreholes

of the affected super structure was carried out. Figures 33 to 35 are taken from Boon and Ooi (2016) showing such a case history of an elaborate pile cutting and underpinning of an existing LRT station without affecting the operation of the rail services.

In many cases, the construction of the temporary works required for cutting the piles may have a more significant impact on the structure than the impact from TBM mining. This is because pile cutting has to be carried from vertical access shaft and horizontal adits in order to reach the section of the pile to be cut and removed (see Figures 34 and 35).

In order to ensure that the existing facilities remains operational during the works, active jacking and close monitoring were strictly enforced and the performance requirements of the projects or the stake holders were complied with (e.g. KTMB and LRT have stringent operational requirements).

\subsection{MANAGING TUNNELLING RISK}

Risk management is an important process to ensure safe and timely delivery of any underground project. At the initial stages, it can be appreciated that the risks are mainly related to design matters, land issues, approvals and third party engagement. The design risk assessment starts from route selection taking into account of the preliminary appraisal of ground or geotechnical risks and the impact of tunnelling on utilities and structures. Once the tunnel alignment and profile is confirmed, the risks assessment evolve to include the selection of TBM to minimise the impact tunnelling works, a closer assessment of structures and building within the tunnel corridor and to ensure that all possible obstructions to tunnelling are identified.

All the risks including the risks discussed earlier along the entire tunnel section are to be evaluated and ranked and captured in a risk register. The risk register provides an overview of the whole project risk and the flexibility to zoom into areas of high risks. Specific workshops on high risks elements to ensure safe and plausible measure are in place to reduce the risks to an acceptable level prior to tunnelling works. The impact of some

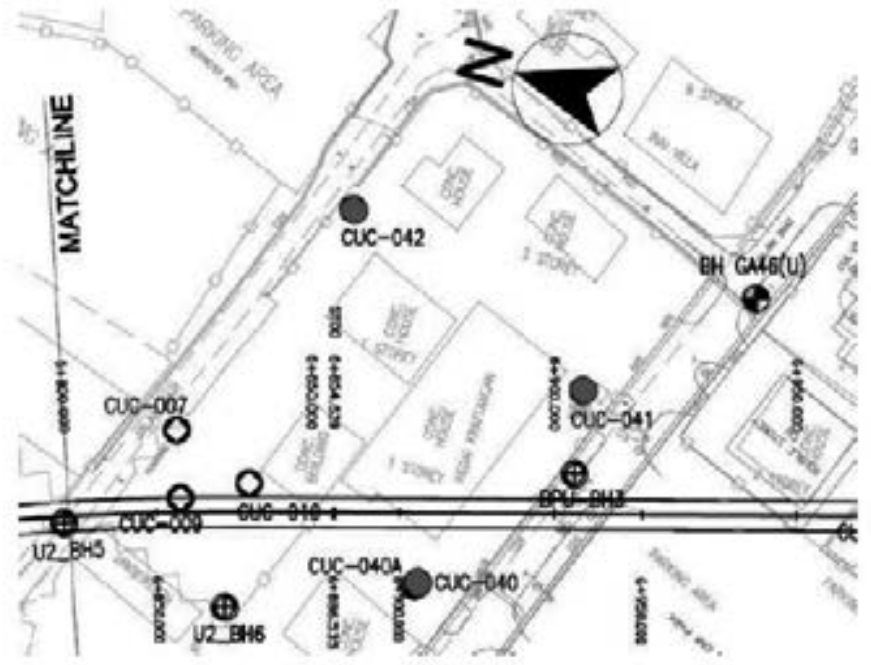

Figure 28a: Plan of investigation around a pre-existing building at the boundary. Red circles are boreholes used to carry out crossholes

Seismic Cross Section of CUC-040a \& CUC-041

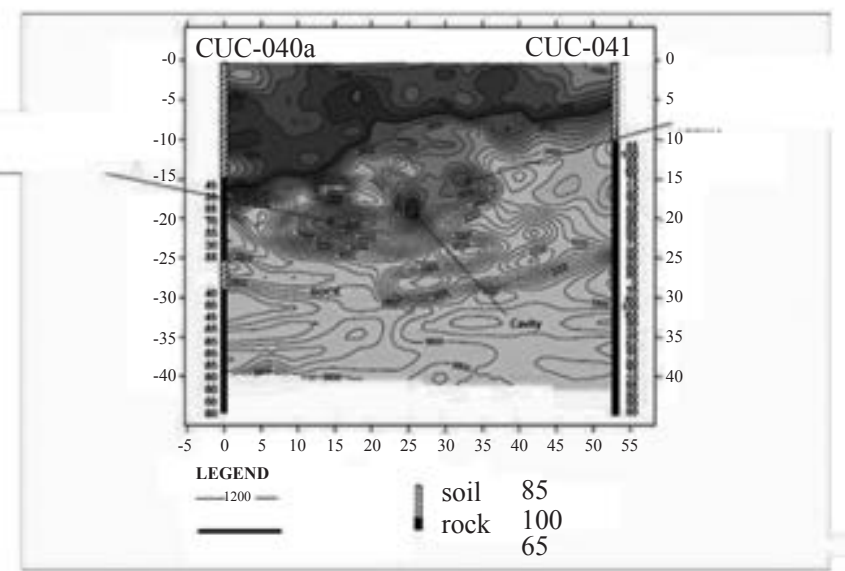

Figure 28b: Cross hole tomography under the structure, with a fractured zone detected. 
Seismic Cross Section of CUC-040 \& CUC-042

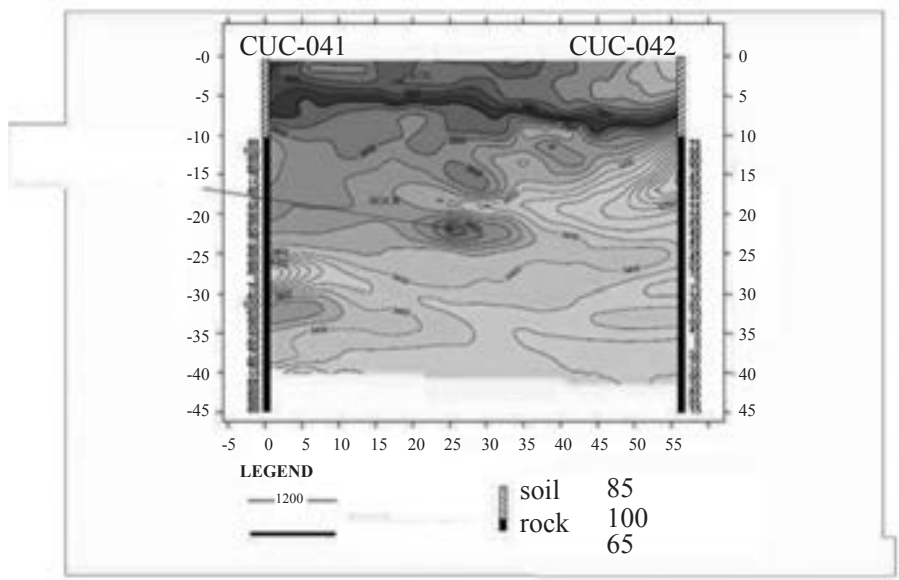

Figure 28b: Cross hole tomography under the structure, with a fractured zone detected.

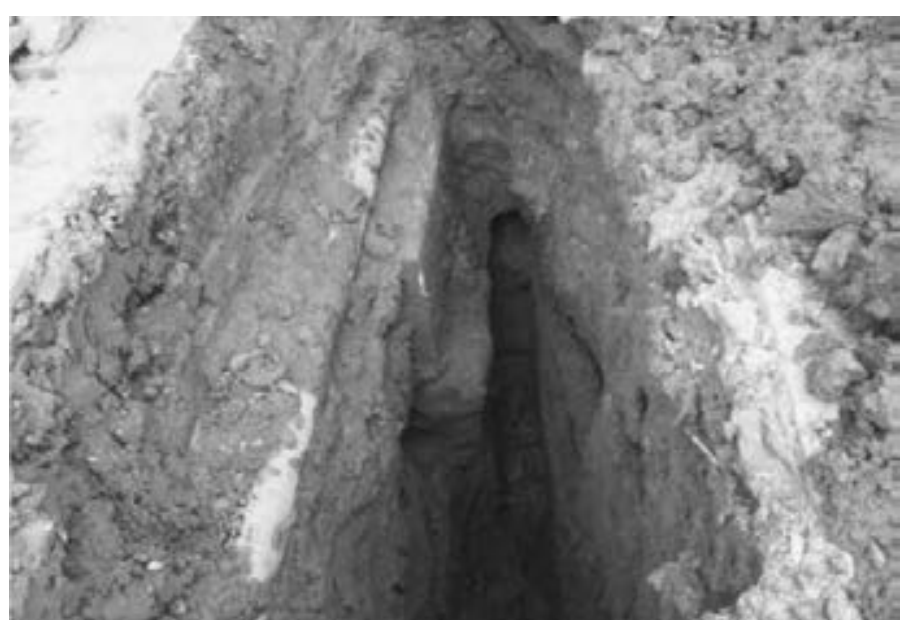

Figure 29: Trial pit to detect size of foundation and type of piles

specific decisions taken to mitigate program risks in this project are presented below.

The most effective mitigation of ground risks to tunnelling is to be able to "look ahead" and know the ground condition ahead of tunnelling. To allow for such possibilities, a lot of TBMs, including the TBMs used for SMART and SBK line were design to allow probing to be carried out through the TBM face. However, probing through these ports would require the TBM to stop mining and this is generally not practiced as it significantly affects the progress of tunnelling works. Alternative "look ahead" methods such as passive seismic techniques, acoustic reflection (also known as sonic soft ground probing (SSP) technique and electrical resistivity (bore-tunnelling electrical ahead monitoring $(B E A M))$ system are available in the tunnelling industry. The SSP method was introduced for the SMART project with the hope to pick up solution features in karst ahead of mixed shield/ slurry TBM mining, there appeared to be poor correlation as the method was discontinued at quite an early stage of the project. The most common approach was advance investigation from ground level ahead of the tunnelling works.

In minimising program risks, the most common approach in underground metro project is to delink the station and tunnelling works. Depending on the number on TBMs, suitable lunch sites, underground stations, utility relocations, land matters and time available, bore through and pull/push through options through shafts and stations may have to be considered.

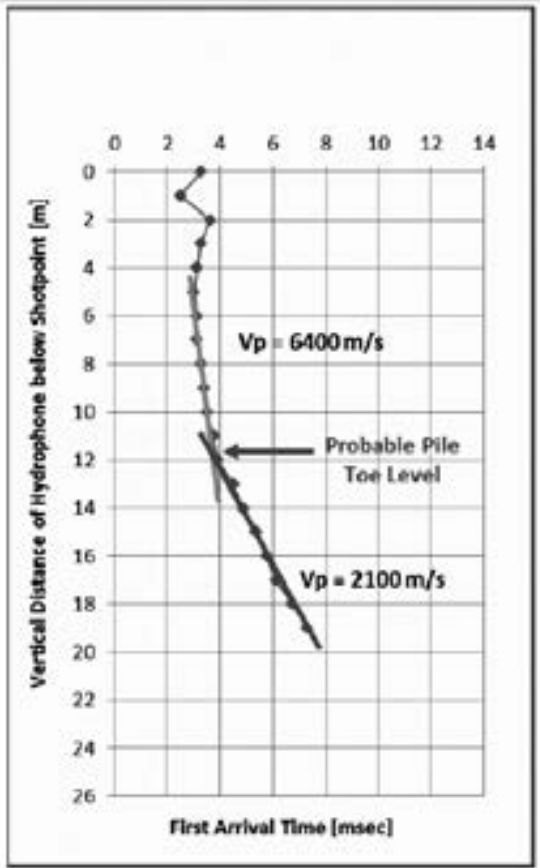

Figure 30: Pile length detection using parallel seismic (inserted Figure 31)
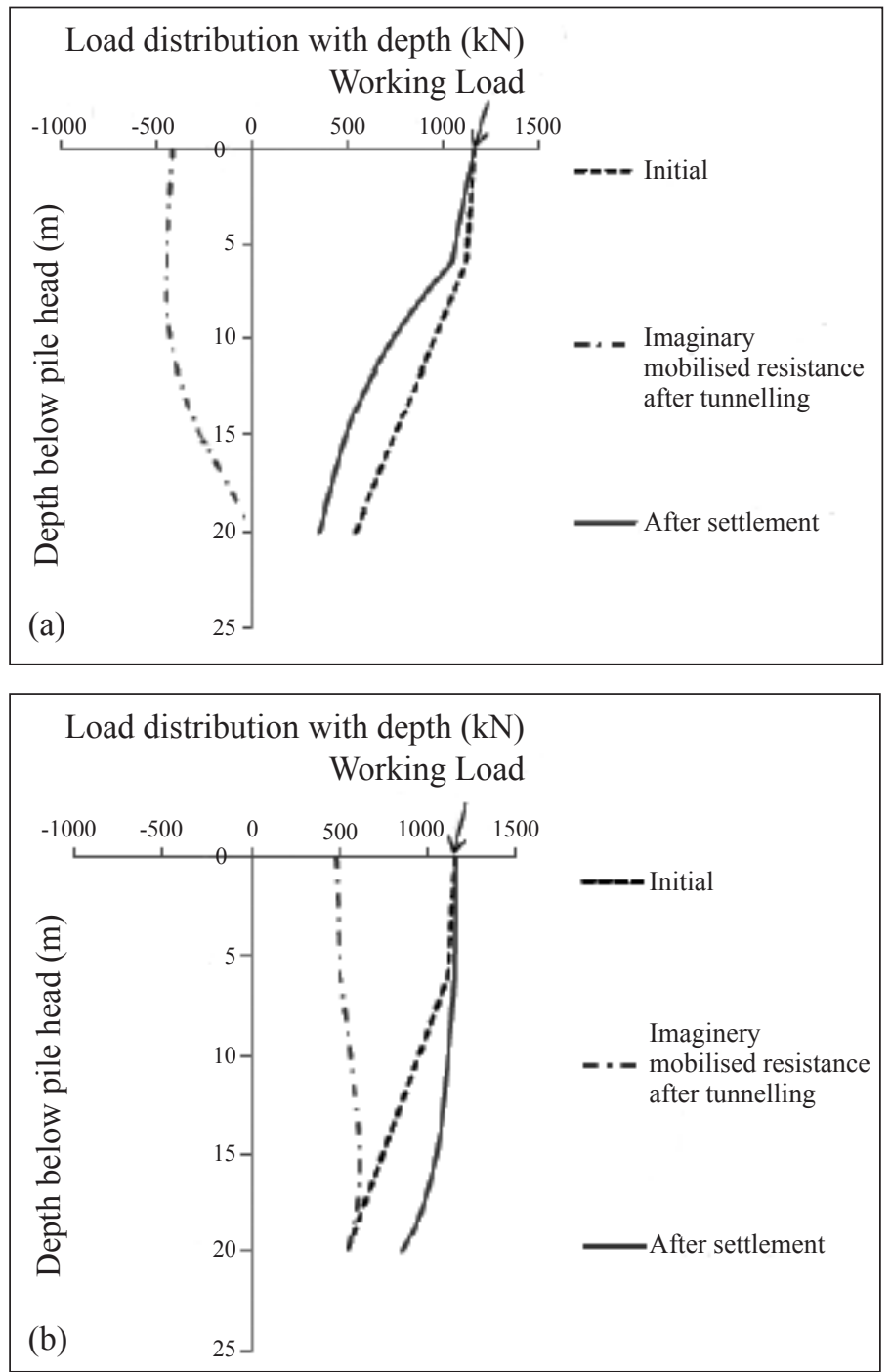

Figure 31: Load redistribution with depth due to tunnel induced settlement (after Boon and Ooi 2016) 


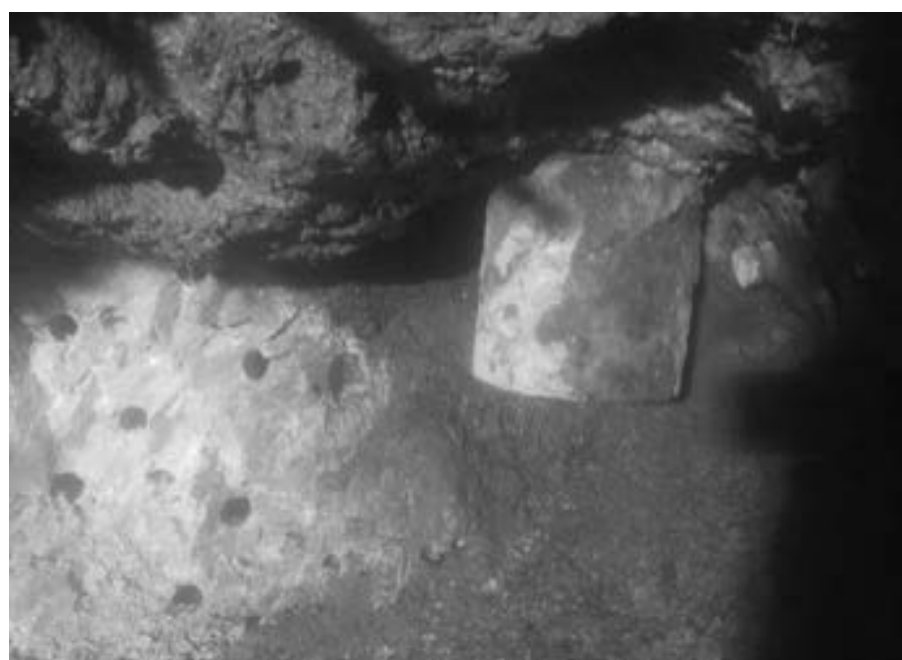

Figure 32: Photo showing API pipe (micropile) encroaching into tunnel horizon

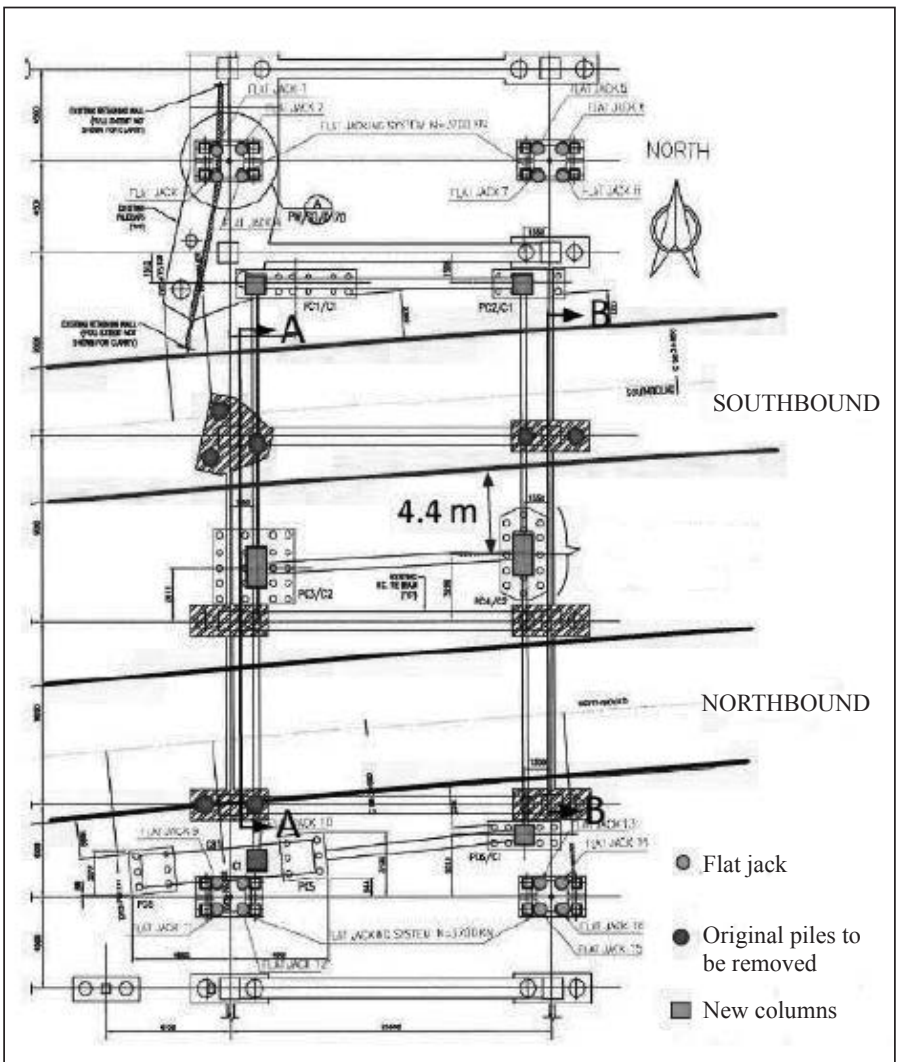

Figure 33: Layout of affected piles at LRT Station (after Boon and Ooi 2016)

In the case of bore through options, some of the considerations include D-wall reinforcement type (glass fibre reinforcements GFR are commonly used) and ground improvement works where TBM cut-through is required. In bore through option two scenarios can occur; completion of D-wall prior to tunnelling or completion of tunnelling prior to D-wall construction. The impact of D-wall excavation on the completed tunnels if bore through is carried out prior to D-walling works. The problems include potential of collapse during $\mathrm{D}$ wall construction due to the low cover between the extrados of the tunnel to the D-wall. The impact of such collapse must be checked to ensure that the tunnel is not adversely affected and the tunnel is still able to support the ongoing tunnelling activities.

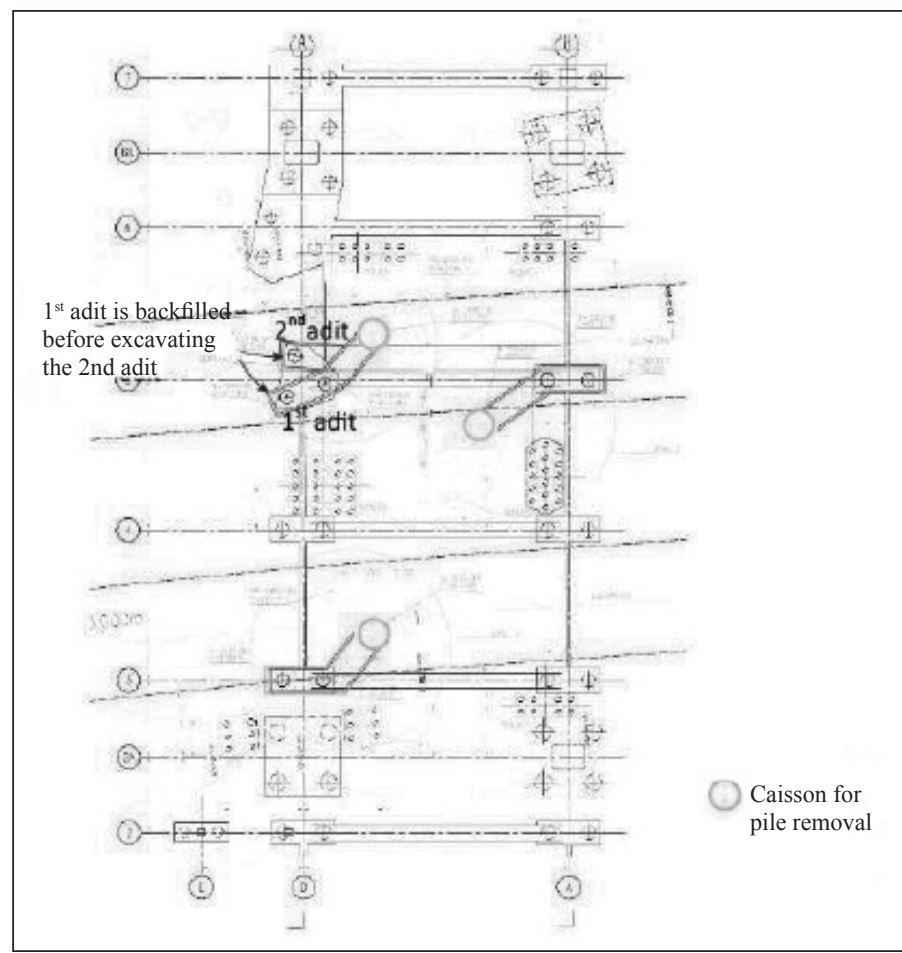

Figure 34: Layout of caisson shaft and adits (after Boon and Ooi 2016)

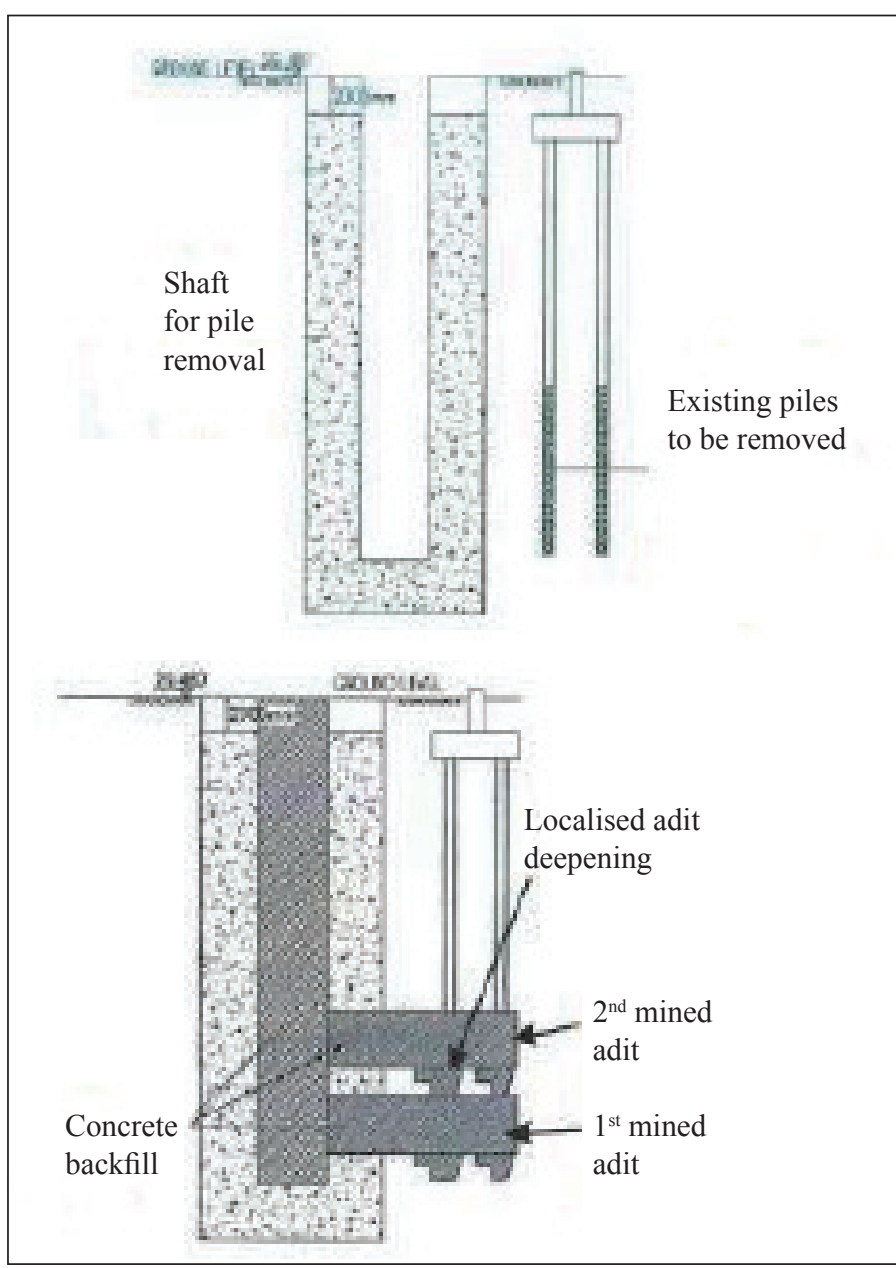

Figure 35: Schematic of shaft and adits for pile removal (after Boon and Ooi 2016) 
The following presents a case history on the case where the D-wall is completed first followed by tunnelling through the station box prior to major excavation works. Figure 36 shows the D-wall deformation before tunnel bore through but after excavation to roof slab level. Figure 37 presents the deformation of the D-wall after both the lower and upper TBM has bored through the station box. The increase in the D-wall deflection and the shift in the shape of the deflection curve due to tunnel bore through is seen by comparing Figures 36 and 37.

The impact of D-wall deformation as a result of stage excavation and the cases with (data points) and without (solid lines) tunnel bore through are compared with the results obtained from PLAXIS analyses and the these information are presented in Figure 38. The bore through option does attract some additional deformation and should be taken into consideration when bore through option is adopted at close proximity to sensitive structures.

In the case, when the tunnel is deep, the impact of excavation above the tunnel to form the station structure needs careful assessment especially in more permeable ground conditions. In some cases, backfilling of the tunnels may be required to ensure stability of the wall and tunnel segmental lining when excavation is carried out above the tunnel. When backfilling of the tunnel is required, the construction program has to be properly assessed to avoid clashing of construction activities, often is best carried out when the tunnel is no longer required for tunnelling operations.

The following present some insight on the measurements and some analytical assessment of the construction of stacked twin tunnels, with the upper tunnel constructed first and subsequently undermined by the lower tunnel. Boon and Ooi (2017) showed that the longitudinal settlement profile of the upper tunnel could be analysed as a Winkler beam. The Winkler beam analyses, with the assumption of loss of support pressure behind the TBM shield, resulted in good agreement with field measurements with regard to the deflected shape of the upper tunnel (settlements normalized by maximum settlement So, which can be estimated from the volume loss induced by tunnelling (Peck, 1969) at different points of interests with respect to the lower TBM face (see Figure 39).

The results in Figure 39 and Figure 40 show that $15 \%$ of the total settlements had taken place above the TBM face, $50 \%$ of total settlements had taken place behind the tunnel shield, and most of the settlements had taken place when the TBM face is 5D away.

The impact of settlement of the second tunnel onto the first tunnel is compared between the case where the upper tunnel is constructed first and also the case where the lower tunnel is constructed first. The results indicate that the magnitudes of settlement could be more than five times larger when the top tunnel is constructed first. This observation is consistent with Addenbrooke \& Potts (2001), where the heave/settlement is more than 4 times when the edge-to-edge separation distance between the lining is approximately its tunnel diameter. The impact is smaller if the bottom tunnel is constructed first because the influence of volume loss onto an object below the tunnel is negligible.

The field measurements of the relative positions between the twin tunnels in dimensionless form, normalised against the radius a are shown in Figure 41. Figure (a) shows the normalised settlement plotted against the normalised horizontal distance between the two tunnel centres. The results show that the impact

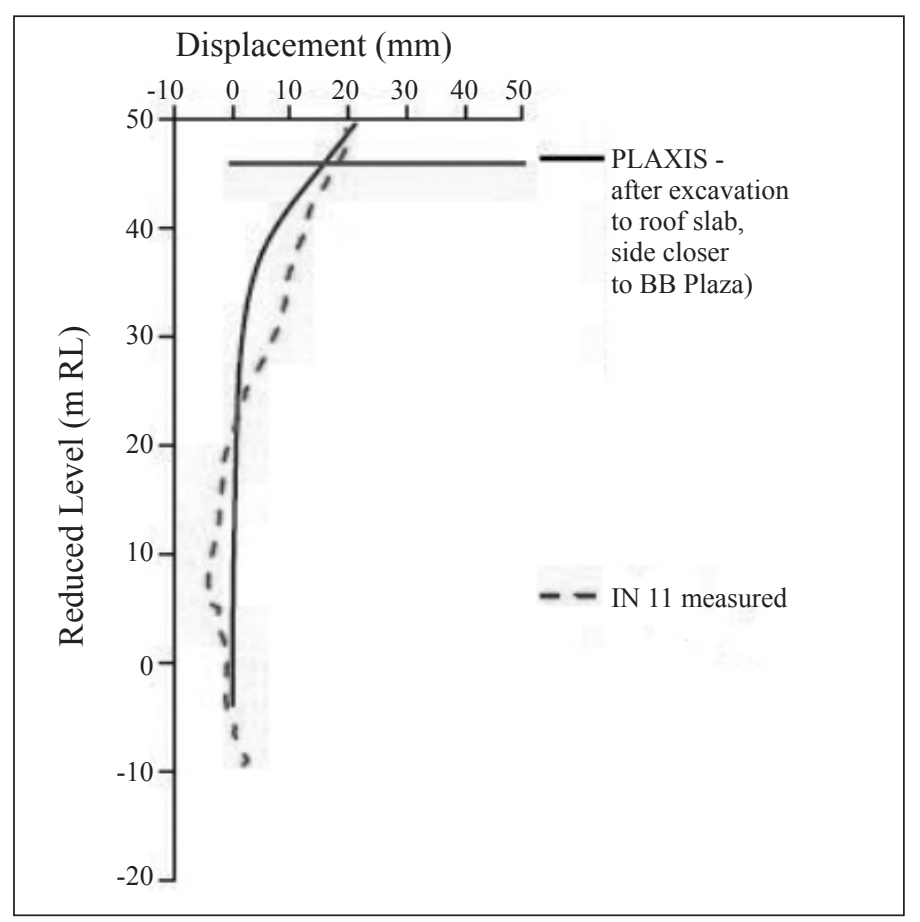

Figure 36: Deflection of D-wall prior to tunnel bore through after completion of roof slab excavation (after Boon and Ooi 2016)

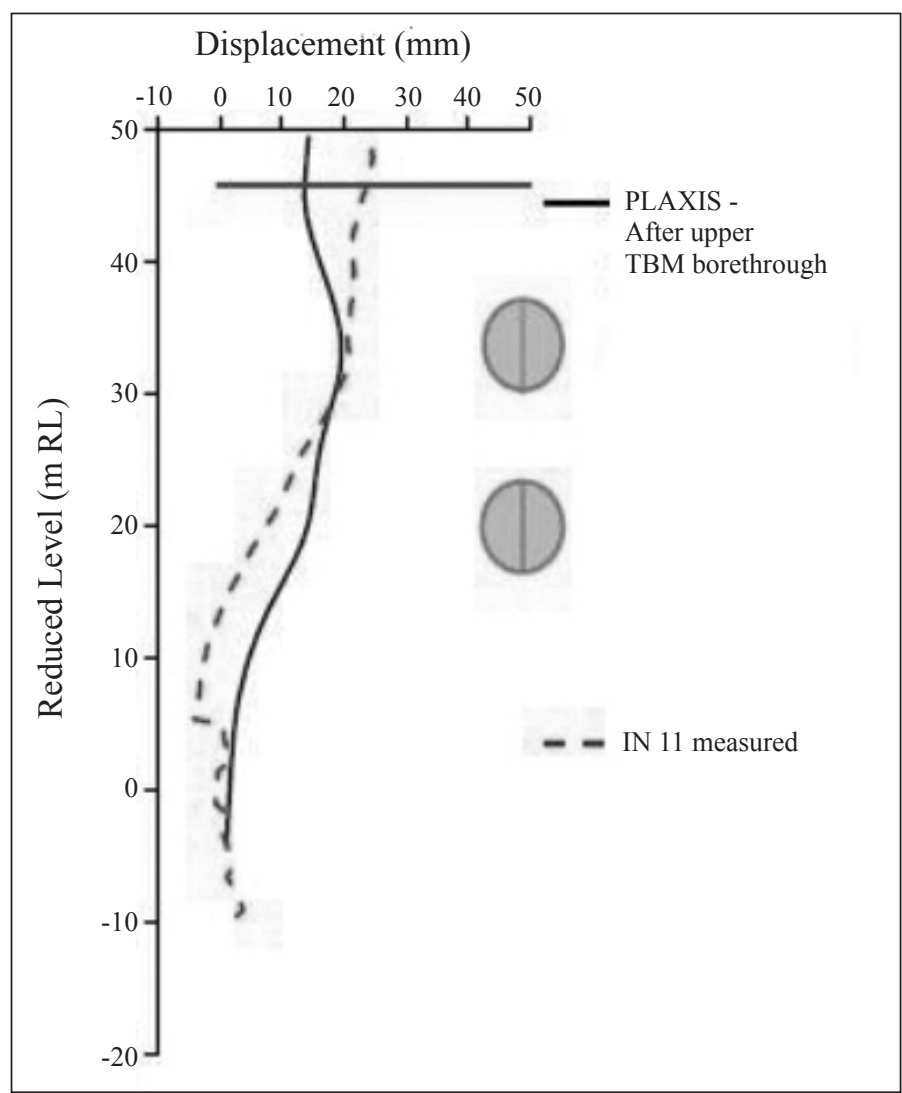

Figure 37: Deflection of D-Wall after bore through of lower and upper tunnel (after Boon and Ooi 2016) 
of TBM undermining is dominant for horizontal distances less than $0.5 \mathrm{D}$ between the tunnel centres. It was found that the horizontal distance between the tunnels had a dominating influence on the measured settlement by comparison to the vertical distance for this geometrical configuration (1D radial separation). Figure (b) is another way of presenting the data, where the influence between two dimensionless groups is linear. Beyond a certain $\mathrm{a} / \mathrm{h}$ value the two tunnels could be considered as directly stacked for practical purposes, the settlement magnitude reaches the limiting value.

The final consideration to complete the underground works is having sufficient experienced crew and supporting staff to complete the underground works. Being the first MRT line there will be a major shortage of trained labourers to support the tunnelling and general construction works. In order to train the workers to fill in these positions the Tunnelling Training Academy (TTA) and the Construction Training Centre (CTC) were established. With the right and crew and support staff working in a safe and well managed site, the works can be completed on time and cost and this was proven in the SBK line where the project was delivered on time and cost.

\subsection{DISCUSSIONS AND CONCLUSIONS}

The inevitable underground transit system will inevitably lead to underground works complete with all the constraints and challenges in both design and construction that is unique to Kuala Lumpur's geology. The major challenges of deep excavation are mainly related to the uncontrolled ground water inflow through solution channels resulting in consequential impacts such as groundwater lowering, ground settlement and sinkholes. When subjected to prolonged dewatering, buildings nearby may be subjected to some damage due to differential settlement. The merits of the different retention system in soil have been briefly discussed. The method of curtain grouting treatment as "cutoff" curtain in advance of excavation in limestone bedrock has been presented. Although the curtain grouting was carried out to "refusal" using closure method (a well-documented approach used as seepage cut-off in dam foundation), it is expected that there will still be many solution channels that would have "missed treatment" by the above method. As a result, further localized seepage treatment is to be planned in tandem with the excavation works. It is believed that without curtain grouting treatment, the frequency and intensity of water inflow into the shaft would have been more serious. Where practical, a physical structural wall would be the most effective "cut-off" system to prevent seepage into the shaft of karstic limestone during excavation. In the light of the above a more robust system of treating the high seepage zflow through localized solution channels warrants further attention and development. The deep excavation and tunneling works and some of the salient aspects of the successfully completed underground section of the Sg. Buloh to Kajang (SBK), Klang Valley Mass Rapid Transit (KVMRT) Project has been presented.

The tunneling works in Kenny Hill Formation of the SBK Line was completed with good control and production rates. As for the case of tunneling through KL Limestone, tunneling through untreated solution features is inevitable. For this project, the versatile VD TBM had successfully addressed all the challenges of tunneling through KL Limestone with relatively few incidences. Some case histories of managing tunnels impacts

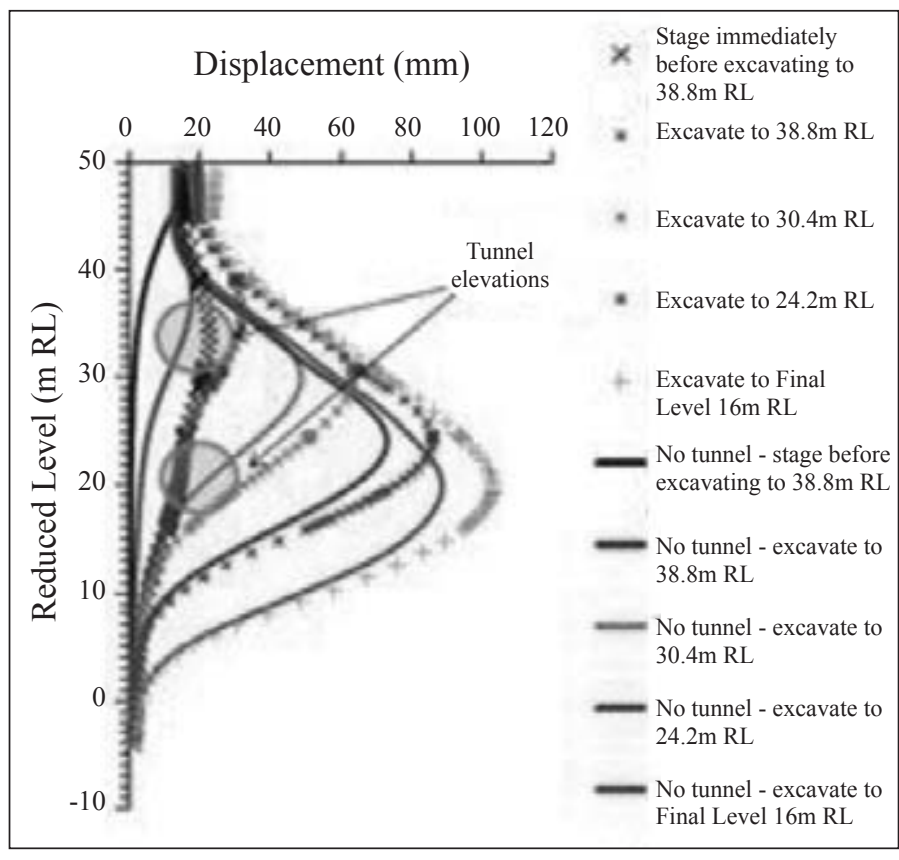

Figure 38: Comparison of D-Wall deflections with stage excavation and cases with and without tunnel bore through (after Boon and Ooi 2016)

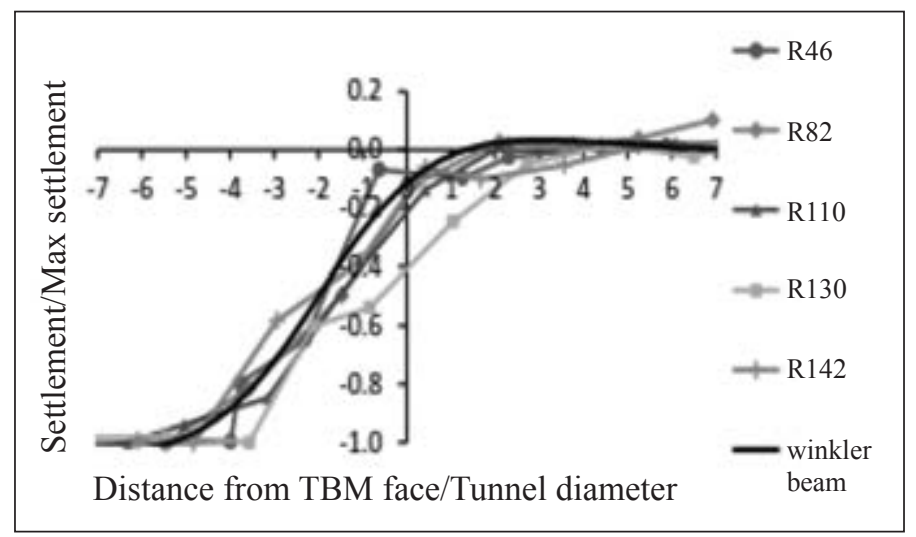

Figure 39: Longitudinal settlement profile obtained by using a specific ring number as a reference point, and measuring the distance of the TBM face (after Boon and Ooi, 2016)

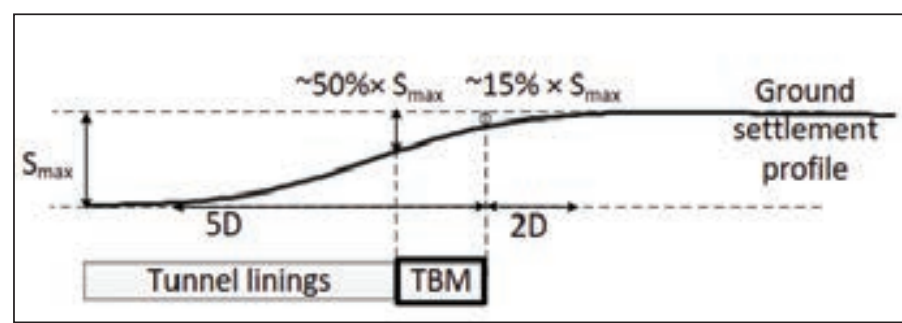

Figure 40: Schematic longitudinal settlement profile of upper tunnel with respect to shield TBM face from findings (after Boon and Ooi, 2016)

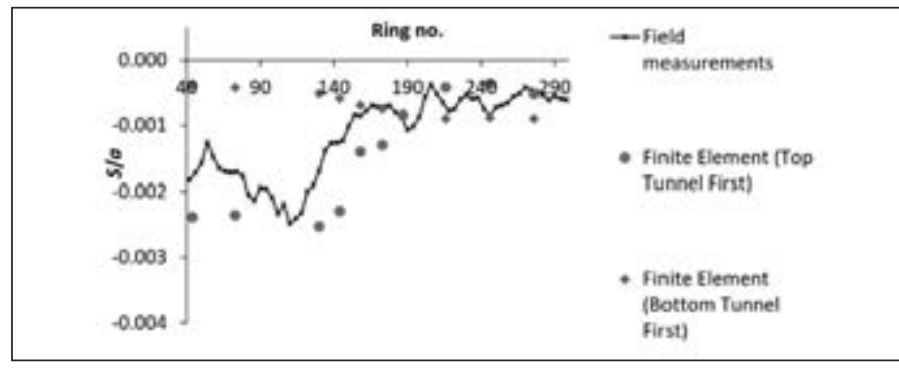

Figure 41: Comparison of construction sequence on settlement 


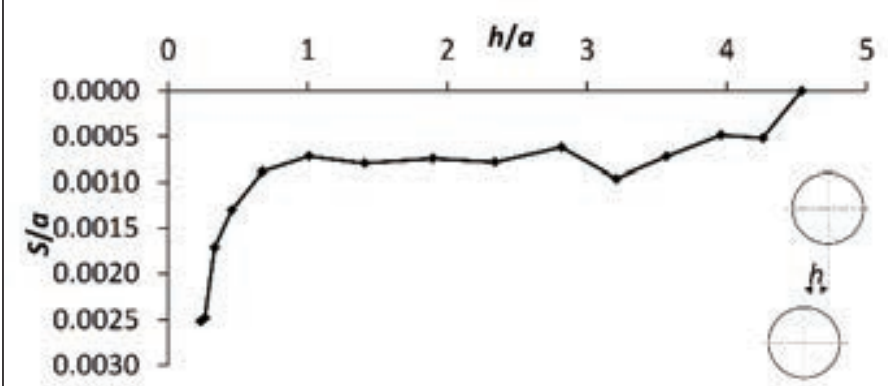

(a)

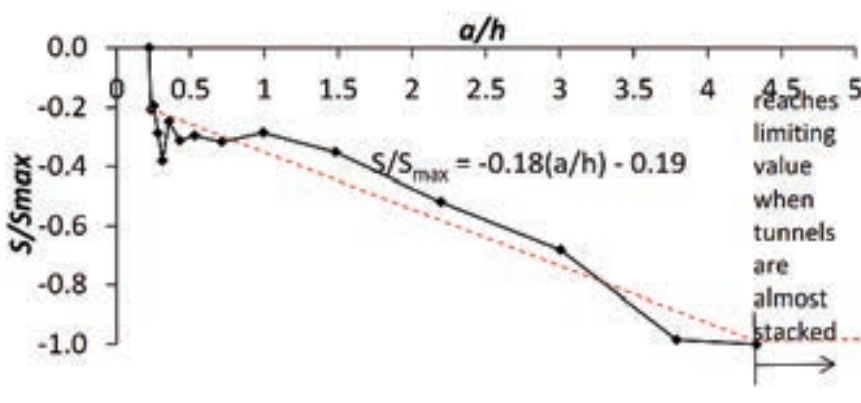

(b)

Figure 42: Decline in settlement as horizontal distance between the tunnel increases where the $x$-axis is (a) h/a and (b) a/h. Edges of tunnels are radially apart by approximately 1-diameter distance

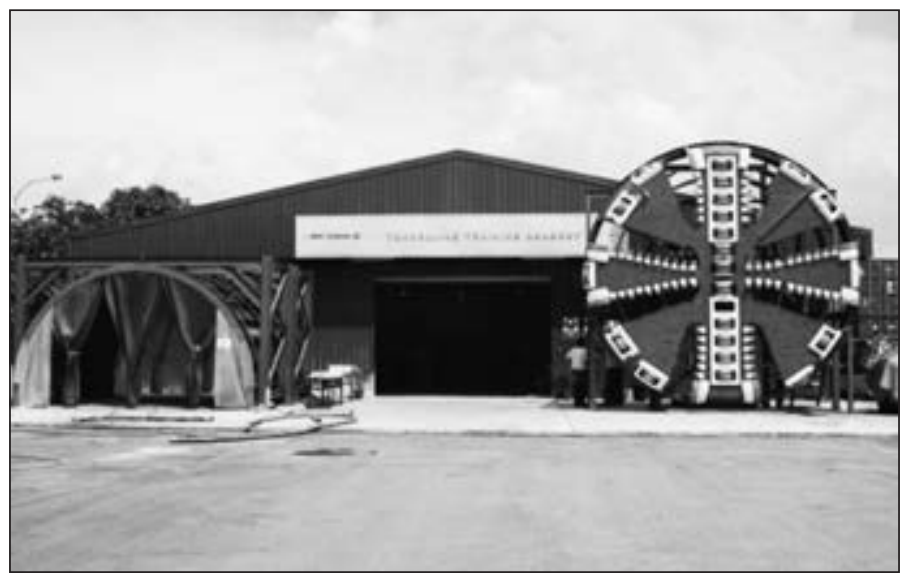

Figure 43: Tunnelling Training Academy (TTA)

and program risks have been presented. The TTA and CTC have been instrumental in training the support crews to meet the gap in human resource to ensure timely completion of the project.

The successful completion of the project is only possible with the dedication and commitment of the client, the management and the support of the many dedicated staff who had laboured tirelessly to complete the project on time and in a safe manner.

\subsection{REFERENCES}

[1] Addenbrooke, T.I. and Potts, D. M. (2001). "Twin tunnel interactions: surface and subsurface effects". The International Journal of Geomechanics, 1(2), 249-271.

[2] Boon, C. W., Teh, E.H., and Ooi, L.H (2015a). "Protection of buildings and structures within the influence of tunnelling works". International Conference and Exhibition on Tunnelling \& Underground Space (ICETUS 2015), 3 - 5 March, Ooi T.A.,
Ooi, L.H. (Eds.), Tunnelling \& Underground Space Division, The Institution of Engineers, Malaysia, 256-262.

[3] Boon, C.W., Ooi, L.H., and Low, Y.Y. (2015b). "Performance of ground anchors in a Mass Rapid Transit project in Malaysia". 9th International Symposium on Field Measurements in Geomechanics (FMGM), 9-11 September, Dight, P. (Eds.), Sydney, Australia, Australian Centre for Geomechanics, 621630 .

[4] Boon, C.W. and Ooi L.H. (2016a). "Tunnelling Past Critical Structures in Kuala Lumpur: Insights from Finite Element Analysis and T-Z Load Transfer Analyses". Geotechnical Engineering Journal of the SEAGS \& AGSSEA, Vol. 47, No.4, pp 109-122.

[5] Boon, C.W. and Ooi, L.H. (2016b). "Type II Factor of Safety: Reliability of Information from Instrumentation, Numerical Analysis, Site Investigation and Design", 19th Southeast Asian Geotechnical Conference \& 2nd AGSSEA Conference (19SEAGC \& 2AGSSEA) Young Geotechnical Engineers Conference, The Institution of Engineers Malaysia, pp 53-58.

[6] Boon, C.W., Ooi, L.H., Tan, J.G., Low, Y.Y. (2016). "Geotechnical considerations of deep excavation design for TBM bore- through with a case history in Kuala Lumpur", Geotechnics for Sustainable Infrastructure Development, Geotec Hanoi 2016, pp 375-384.

[7] Burd, H.J., Houlsby, G.T, Augarde, C.E, and Liu, G, (2000). "Modelling Tunnelling-Induced Settlement of Masonry Buildings". Proc. ICE, Geotechnical Engineering, 143, 17-29. Chakeri, H., Hasanpour, R., Hindistan, M. A., and Unver, B. (2011). "Analysis of interaction between tunnels in soft ground by 3D numerical modelling”. Bull Eng Geol Environ, 70, 439448.

[8] Chen, R.P., Zhu, J., Liu, W., and Tang, X.W. (2011). "Ground movement induced by parallel EPB tunnels in silty soils". Tunnelling and Underground Space Technology, 26, 163- 171.

[9] Chin, R. M., Salehuddin, M. S. and Husairi, N. A. (2015). "Performance of EPB Tunnelling in Kenny Hill". International Conference and Exhibition on Tunnelling \& Underground Space (ICETUS 2015), 3 - 5 March, Ooi T.A., Ooi, L.H. (Eds.), Tunnelling \& Underground Space Division, The Institution of Engineers, Malaysia, 298-301.

[10] Cording, E. J., (1991). "Control of ground movements around tunnels in soil". Proc. 9th Pan-American Conf. Soil Mech. Found. Engng, Valparaiso, 2195-2244.

[11] Ha, T. T. and Ooi, L. H. (2016). "Positioning to undertake underground works contracts - a Malaysian experience". Southeast Asian Conference and Exhibition in Tunnelling and Underground Space 2017 (SEACETUS 2017), Subang Jaya, Malaysia, 18-19 April 2017, pp 39-50.

[12] Goh, C. Y., Lim, Y. S, Ong, K. S., Challenges of a Deep Excavation at an Urban Area, International Conference and Exhibition on Tunnelling \& Underground Space (ICETUS 2015), 3 - 5 March, Ooi T.A., Ooi, L.H. (Eds.), Tunnelling \& Underground Space Division, The Institution of Engineers, MalaysiaInternational Conference and Exhibition of Tunnelling and Underground Space, IEM Kuala Lumpur, 3-5 March 2015.

[13] Klados, G., Ng, H.W., Wong, G.C.Y., and Chin, J.H.H., (2015). "Managing tunnelling challenges through Kuala Lumpur karst formation using variable density TBMs". International Conference and Exhibition on Tunnelling \& Underground Space (ICETUS 2015), 3 - 5 March, Ooi T.A., Ooi, L.H. (Eds.), 
Tunnelling \& Underground Space Division, The Institution of Engineers, Malaysia, 186-191.

[14] Lee, R.G., Rowe, R.K., and Lo, K.Y., (1992). "Subsidence owing to tunnelling I: Estimating the gap parameter". Canadian Geotechnical Journal, 29, 929-940.

[15] Lim, H.Y. and Ng, H.W., (2015). "Steel Fibre Reinforced Concrete Tunnel Lining Segments". International Conference and Exhibition on Tunnelling \& Underground Space (ICETUS 2015), 3 - 5 March, Ooi T.A., Ooi, L.H. (Eds.), Tunnelling \& Underground Space Division, The Institution of Engineers, Malaysia, 198-207.

[16] Loganathan, N. and Poulos, H.G. (1998). "Analytical prediction for tunneling-induced ground movements in clays". J. Geotech. and Geoenvir. Eng. 124(9), 846-856.

[17] Loganathan, N. (2011). "An innovative method for assessing tunnelling-induced risks". Parsons Brinckerhoff 2009 William Barclay Parsons Fellowship Monograph 25. First Printing 2011, New York.

[18] Mair, R.J., Taylor R.N., and Bracegirdle, A. (1993). "Subsurface settlement profiles above tunnels in clays". Géotechnique 43(2), 315-320.

[19] Mair, R. J. (2008). "Tunnelling and geotechnics: new horizons". Géotechnique 58(9), 695-736.

[20] Mair, R.J. and Taylor, R.N., (1993). "Prediction of clay behaviour around tunnels using plasticity solutions". Predictive Soil Mechanics: Proceeedings of the Wroth Memorial Symposium, Oxford, 27-29 July 1992, Thomas Telford London, 449-463.

[21] Muir-Wood, A.M., (1975). "The Circular Tunnel in Elastic Ground”. Géotechnique, Vol. 25 (1) 115-127.

[22] Ooi, L. H., and Ha, T.T. (2016a) "The challenges of tunnelling works in Kuala Lumpur karsts". 19th Southeast Asian Geotechnical Conference \& 2nd AGSSEA Conference (19 SEAGC \& 2AGSSEA), Kuala Lumpur (31 May-3 June), pp $1151-1158$.

[23] Ooi, L. H., and Ha, T.T. (2016b) "Deep excavations works in Kuala Lumpur karsts - some considerations". 19th Southeast Asian Geotechnical Conference \& 2nd AGSSEA Conference (19 SEAGC \& 2AGSSEA), Kuala Lumpur (31 May-3 June), pp 8390.

[24] Ooi, T.A., Khoo, C.M. (2017). "Tunnelling activities in Malaysia- a review". Southeast Asian Conference and Exhibition in Tunnelling and Underground Space 2017 (SEACETUS 2017), Subang Jaya, Malaysia, 18-19 April 2017, pp. 243-252.
[25] Poh, S.T., Low, Y.Y., Ooi, L.H. (2014). "Steel fibre reinforced concrete tunnel lining for a metro project - a Malaysian Experience". Proceedings of the 12th International Conference on Concrete Engineering and Technology (CONCET 2014), 8794.

[26] Poulos, H.G., and Deng, W. (2004). "An investigation on tunnelling-induced reduction of pile geotechnical capacity". Proc. 9th Australia-New Zealand Conf. On Geomechanics, Auckland, Vol. 1, 116-122.

[27] Tan, B. K. and Ch'ng, S. C., 1986, Weak soil above limestone bedrock. Newsletter of the Geological Society of Malaysia, No. 2, Vol. 12 (1986).

[28] Tan, J.G., Ooi, L.H., Yeoh, H.K. (2015). "Considerations of Deep Excavation in Kenny Hill and Kuala Lumpur Limestone Formations". International Conference and Exhibition on Tunnelling \& Underground Space (ICETUS 2015), 3 - 5 March, Ooi T.A., Ooi, L.H. (Eds.), Tunnelling \& Underground Space Division, The Institution of Engineers, Malaysia, 208-219.

[29] Tan S. M., 2005, Karstic Features of Kuala Lumpur Limestone, Jurutera, Institution of Engineers Malaysia

[30] Thewes, M., and Budach C. (2009). "Grouting of the annular gap in shield tunnelling - An important factor for minimisation of settlements and production performance", ITA-AITES World Tunnel Congress 2009, Safe Tunnelling for the City and Environment, 23-28 May.

[31] Vaughan, P. R., Maccarini, M., Mokhtar, S. M. (1988). "Indexing engineering properties of residual soil”. Quarterly Journal of Engineering Geology and Hydrogeology, 21, pp 69-84.

[32] Waltham, A.C. and Fookes, P.G (2003). "Some Engineering classification of karst ground conditions. Quarterly Journal of Engineering Geology and Hydrogeology, 36.

[33] Wong, J. and Muhinder, S. (1996). "Some engineering properties of weathered Kenny Hill Formation in Kuala Lumpur", Proceedings of the 12th South East Asian Geotechnical Conference, 1, 179-187.

[34] Yeap E.B., 1986, Irregular Topography of The Subsurface Carbonate Bedrock in The Kuala Lumpur Area, Foundation Problems in Limestone Areas of Peninsular Malaysia, Geo. Eng. Tech. Div., IEM. 